\title{
A Review on Carbon Nanotubes (CNT): Structure, Synthesis, Purification and Properties for Modern day Applications
}

\author{
Nur-Azzah Afifah Binti Taib \\ Universiti Malaysia Sarawak \\ Md. Rezaur Rahman \\ Universiti Malaysia Sarawak \\ Mohammed Mahbubul Matin \\ University of Chittagong \\ Jamal Uddin \\ Coppin State University
}

Muhammad Khusairy Bin Bakri ( $\nabla$ kucaigila@yahoo.com)

Universiti Malaysia Sarawak https://orcid.org/0000-0003-1971-2350

Afrasyab Khan

South Ural State University: Uzno-Ural'skij gosudarstvennyj universitet

\section{Research Article}

Keywords: Biomedical application, Chemical vapor deposition (CVD), Single-walled CNTs, Toxicity

Posted Date: September 28th, 2021

DOI: https://doi.org/10.21203/rs.3.rs-930166/v1

License: (-) (1) This work is licensed under a Creative Commons Attribution 4.0 International License. Read Full License 


\section{Abstract}

Carbon nanotubes (CNTs), composed of graphene/graphite sheets, have been used since the 1990s and become one of the most important materials owing to its massive applications in energy, environmental and life sciences. In general, there are two types of known CNTs such as single-walled CNTs (SWCNTs) and multi-walled CNTs (MWCNTs). They have broader and novel fields of application in the fabric and textile industries, wastewater treatment, energy storage, and also as structural reinforcement materials. CNTs are reported to synthesize by arc discharge, laser ablation and chemical vapor deposition (CVD) methods where CVD technique is found to be the most versatile and largely used method. In all the methods synthesized CNTs contain various degrees of impurities which are purified by oxidation treatment, ultra-sonication, magnetic purification, etc. CNTs have wide range of industrial applications due to their remarkable mechanical, thermal, electrical, chemical and biological properties. In this review, medical and biomedical applications of CNTs and CNTs-based composites are specially focused due to their significant applications in these fields along with their structure, classification, preparation and related properties. Besides, CNTs' toxicity and biosafety, especially on the human body, are also discussed in this review article.

\subsection{Introduction}

Carbon is one of the most common elements on the planet, and it can take on a wide range of crystalline structures. Since carbon has a tetravalency, it contains $s p^{3}$ hybridization. Carbon is a fascinating product because it occurs in eight different allotropes, one of which is carbon nanotubes (CNTs), which belongs to the group of nano-sized carbons or nanocarbons (Rahman et al., 2019; Raunika et al., 2017). Since they have a micrometer-sized volume and a nanometer-sized diameter, CNTs have a length-to-diameter ratio of over 1000. Aside from that, they had the same atom composition as graphite, with hexagonally organized atoms. CNTs are a carbon allotrope that exists between fullerenes and graphite (Aqel et al., 2012).

Similar to CNTs' building block grapheme they are boned with $s p^{2}$ bonds which is responsible for their extremely strong molecular interaction along with van der Waals forces, and resulted to join them naturally with low-weight ultra-high strength with electrical properties due to $\pi$ bond (Aqel et al., 2012). This also makes CNTs highly attractive for several significant applications and results the introduction of a revolution in the nanotechnology field. Thus, in the current review most of the significant applications of CNTs are compiled along with their classification, structure, preparation and purification.

\subsection{Carbon Nanotubes (Cnts): History}

Even though carbon has been used for over 6000 years, the next advances in carbon did not occur until the late 1980s. The discovery of other stable, ordered structures besides graphite and diamond sparked the quest for new sources of carbon. With their fortuitous observation of the $\mathrm{C}_{60}$ in 1985 , it opened the way for the systematic analysis of carbon filaments of exceedingly small diameters, which has sparked a lot of interest in CNTs. The study had brought fullerenes into the spotlight with the synthesis of carbon clusters with various sizes, properties and structure (Aqel et al., 2012; Ghasempour \& Narei, 2018). This is since $\mathrm{C}_{60}$ was made using a basic arc evaporation apparatus that was widely available in many laboratories (Aqel et al., 2012). Sumio lijima, a Japanese physicist, discovered carbon nanotubes in 1991 while studying carbon compounds under an electron microscope. These needle-like materials were later confirmed to have graphite structure and are now known as carbon nanotubes (CNTs) (Bera, 2017). The first observation of multi-walled carbon nanotubes (MWCNTs) occurred when hard deposits on the cathode were formed using electric arc experiments to shape fullerenes. Meanwhile, two independently conducted experiments in 1993 confirmed the development of single-walled carbon nanotubes (SWCNTs) (Raunika et al., 2017). While carbon nanotubes had been known for a long time before lijima's invention, CNT-related research began only when they discovered that these new fibers had a variety of unique properties. Since such tubes were structurally imperfect prior to this, their properties were not especially important (Aqel et al., 2012). As a result, recent studies and analysis have focused on improving the quality of CNTs generated. Due to their inherent intriguing properties, carbon nanotubes are a major substance in nanotechnology fields and the future novel applications (Kaur et al., 2018).

\subsection{Classification Of Cnts}

Carbon nanotubes are divided into two types: (i) single-walled carbon nanotubes (SWCNTs) and (ii) multi-walled carbon nanotubes (MWCNs). SWCNT is made up of just one sheet of graphene and has a simple structure that allows it to be twisted effortlessly. It also had a low purity (Kaur et al., 2018). SWCNT was created by rolling a single layer of graphite (a different term for graphene) into a smooth cylinder (long wrapped graphene sheets). Since the length to diameter ratio of CNT is about 1000, it is known to be a virtually one-dimensional object. As a result, the majority of SWCNTs had a diameter of 1-2 nm. This structure is often thinner than multi-walled tubes, with a circular outline rather than a linear one. The sidewall of the tube and the end cap of the tube are the next two distinct regions in the SWCNT. Each area had its own set of physical and chemical characteristics. SWCNTs are a more significant variation of a CNT than MWCNT variations. This is because they exhibit critical electric properties that the MWCNT varieties do not. Electric wire is the most fundamental building block of these devices, and SWCNT can be an outstanding conductor (Aqel et al., 2012). It can also be semiconducting or metallic based on their helical angle $(X)$. SWCNTs have thus been the focus of nanotechnology science for the past two decades (Rao et al., 2018). SWCNTs are also expensive to produce, and their synthesis necessitates the use of a catalyst. As a result, developing cost-effective synthesis methods is critical for the future of carbon nanotechnology (Aqel et al., 2012; Kaur et al., 2018).

In the MWCNT the arrangement is made up of two or more aligned rolled sheets of graphene, and it has a complicated structure that makes it difficult to twist in this shape. As a result, unlike SWCNT, MWCNT had a high purity (Ghasempour \& Narei, 2018; Kaur et al., 2018). Multiple layers of graphite of varying diameters were rolled in on themselves to create the tube structure of the multi-walled, and both ends of such tubes were often closed. In other words, these multi-walled carbon tubes would be made up of a series of concentric SWCNTs. The outer diameter of these tubes varied between $3 \mathrm{~nm}$ to $30 \mathrm{~nm}$. Since the length and diameter of these structures vary from those of single-walled carbon tubes, their properties often differ. MWCNTs have an interlayer spacing of

Page $2 / 22$ 
around 3.3 $\AA$, which is similar to the distance between graphene layers in graphite (Aqel et al., 2012). Furthermore, no catalysts are needed in the production of these multi-walled carbon tubes (Kaur et al., 2018). Figure 1 depicted the two kinds of carbon nanotubes, while Table 1 compared the two types of CNTs.

Table 1

Comparison between single-walled and multi-walled CNT

\begin{tabular}{|c|c|c|c|}
\hline $\begin{array}{l}\text { Characteristics/ } \\
\text { or basis of the } \\
\text { properties }\end{array}$ & Single-walled CNT & Multi-walled CNT & References \\
\hline $\begin{array}{l}\text { Number of } \\
\text { graphene layer }\end{array}$ & Single layer of graphene & Multiple layers of graphene & $\begin{array}{l}\text { (Saifuddin et al., } \\
\text { 2013) }\end{array}$ \\
\hline $\begin{array}{l}\text { Presence of } \\
\text { catalyst during } \\
\text { synthesis }\end{array}$ & Catalyst is required for synthesis & $\begin{array}{l}\text { Can be produced without } \\
\text { catalyst }\end{array}$ & $\begin{array}{l}\text { (Kaur et al., } \\
\text { 2018) }\end{array}$ \\
\hline Bulk synthesis & $\begin{array}{l}\text { Bulk synthesis is difficult as it requires proper control overgrowth and } \\
\text { atmospheric condition }\end{array}$ & Bulk synthesis is easy & $\begin{array}{l}\text { (Saifuddin et al., } \\
\text { 2013) }\end{array}$ \\
\hline $\begin{array}{l}\text { Structure of } \\
\text { CNT }\end{array}$ & Not fully dispersed, and form bundled structures & $\begin{array}{l}\text { Homogeneously dispersed with } \\
\text { no apparent bundled formation }\end{array}$ & $\begin{array}{l}\text { (Ali et al., 2014; } \\
\text { Saifuddin et al., } \\
\text { 2013) }\end{array}$ \\
\hline Resistivity range & Resistivity usually in the range of $10^{-4}-10^{-3} \Omega$.m & $\begin{array}{l}\text { Resistivity usually in the range of } \\
1.8 \cdot 10^{-5}-6.1 \cdot 10^{-5} \Omega . m\end{array}$ & $\begin{array}{l}\text { (Deshpande \& } \\
\text { Mahendru, 2018; } \\
\text { Saifuddin et al., } \\
\text { 2013) }\end{array}$ \\
\hline Purity of CNT & $\begin{array}{l}\text { Purity is poor. Typical SWCNT content is as-prepared samples by chemical } \\
\text { vapor deposition (CVD) method is about } 30-50 w t \% \text {. However high purity up } \\
\text { to } 80 \% \text { has been reported by using arc discharge synthesis method. }\end{array}$ & $\begin{array}{l}\text { Purity is high. Typical MWCNT } \\
\text { content is as-prepared samples } \\
\text { by CVD method is about 35- } \\
90 \mathrm{wt} \% \text {. }\end{array}$ & $\begin{array}{l}\text { (Kaur et al., } \\
\text { 2018; Saifudddin } \\
\text { et al., 2013) }\end{array}$ \\
\hline $\begin{array}{l}\text { Defect in } \\
\text { structure }\end{array}$ & A chance of defect is more during functionalization & $\begin{array}{l}\text { A chance of defect is less } \\
\text { especially when synthesized by } \\
\text { arc-discharged method }\end{array}$ & (Ali et al., 2014) \\
\hline $\begin{array}{l}\text { Characterization } \\
\text { of structure }\end{array}$ & Characterization and evaluation are easy & It has very complex structure & (Ali et al., 2014) \\
\hline $\begin{array}{l}\text { Flexibility of } \\
\text { CNT }\end{array}$ & It can be easily twisted and are more pliable & It cannot be easily twisted & $\begin{array}{l}\text { (Kaur et al., } \\
\text { 2018) }\end{array}$ \\
\hline
\end{tabular}

\subsection{Structure Of Cnts}

CNTs are graphene sheets rolled into small, long cylinder tubes with hexagon on their surfaces, i.e., hexagonal carbon cycles. CNTs are part of the fullerene structural family and have incredible thermal, mechanical, and electrical properties, with a length to diameter ratio more than $10^{6}$ (Raunika et al., 2017 ; Zaporotskova et al., 2016). Furthermore, there are several ways to roll a graphene layer, allowing to produce various forms of CNTs (Aqel et al., 2012). Apart from that, the CNTs' chemical bonds are $s p^{2}$ bonds, analogous to graphite, but can be distinguished by their curvature. Quantum confinement and $\sigma-\pi$ rehybridization have been achieved by causing three $\sigma$ bonds to be partially out of plane and compensating by delocalizing the orbital further beyond the tunnel. As a result, CNTs are superior to graphite in terms of mechanical strength, thermal and electrical conductivity, and chemical and biological activity (Ghasempour \& Narei, 2018).

CNTs vary from carbon fibers in that they are made up of strands of layered-graphite sheets rather than single molecules (Saifuddin et al., 2013). SWCNTs can be classified into three types tubes: (i) armchair ( $d=0.407 \mathrm{~nm}$ ), (ii) zigzag ( $d=0.393 \mathrm{~nm})$, and (iii) chiral ( $d=0.414 \mathrm{~nm})($ Rakhi, 2019$)$. The type of SWCNT formed depends on the orientation of the graphene sheets when they are rolled. After that, the chiral vector is used to describe or call the CNTs, which specifies how the graphene sheet is rolled up (Aqel et al., 2012). The chiral vector is represented by two integers, $\mathrm{n}$ and $\mathrm{m}$, which correspond to the unit vector numbers in the graphene honeycomb crystal lattice's two directions (Saifuddin et al., 2013). In the planar graphene sheet, two atoms are selected, and one is used as origin. The chiral vector $\mathrm{C}$ can be defined using the formula in Equation (1).

$\mathrm{C}=\mathrm{na}_{1}+\mathrm{ma}_{2}$

Where, $a_{1}$ and $a_{2}$ are the unit cell vectors of the two-dimensional graphene sheets. The chiral vector points from the first to the second particle, and the CNT axis runs perpendicular to this chiral vector. The length of $\mathrm{C}$ determines the circumference of the CNT, which is determined by the Equation (2).

$c=|C|=a \sqrt{\left(n^{2}+n m+m^{2}\right.}$

where $a$ is the value of the length of unit cell vector $a_{1}$ or $a_{2}$.

The graphical representation of the vector forms for classification and also used to differentiate the CNT structures is presented in Figure 2 . As can be seen in Figure 2, the integers have the following values:

- $m=0$ for all zig-zag tubes and $\left(\theta=30^{\circ}\right)$; 
- $n=m$ for all armchair tubes and $\left(\theta=0^{\circ}\right)$; and

- Or else, if $n \neq m$, it is chiral tube and $\left(0^{\circ}<\theta<30^{\circ}\right)$.

The $(n, m)$ values were used to establish the chirality of the CNTs, which had an effect on their optical, mechanical, and electronic properties. The three CNT structures are presented in Figure 3. The armchair and zig-zag tubes structures, which led to the hexagons' alignment around the radius, provided a high degree of symmetry. Meanwhile, the most common type of CNTs is chiral tube formation, which may occur in two mirror-related shapes (Aqel et al., 2012).

In addition, three models were employed to describe the shape of MWCNTs, based on electron microscopy studies: coaxial cylindrically curved, coaxial polygonised and scrolled graphene sheet. The most common and generally recognized MWCNTs are the coaxial cylindrical models, but those with big tube sizes are the coaxial polygonised model form (Rakhi, 2019). The Russian Doll and Parchment model can also be used to explain the arrangement of MWCNTs. The sheets of graphite in the former model are arranged as a SWCNT inside a wider SWCNT in a concentric cylinder. Meanwhile in the latter model, MWCNT resemble a scroll of parchment or rolled newspaper as a single sheet of graphite is rolled in around itself (Varshney, 2014).

However, in practice, CNT contains defects that form during synthesis, so it does not have the ideal or flawless structure that it does in principle. At the defect site, around $1-3 \%$ of the carbon atoms of a nanotube are located there. The Stone-Wales fault is one of the most common types of flaws, and it is also known as the 7-5-5-7 flaw because there are two sets of five- and seven-membered rings. Due to this type of defect, the curvature of the CNTs usually displays local deformation. More importantly, addition reactions are more favorable at the carbon-carbon double bonds in this defect site (Karimi et al., 2015).

\subsection{Synthesis Of Carbon Nanotubes (Cnts)}

There are many methods for synthesizing CNTs (Fig. 4), however, the three most common methods such as arc discharge, laser ablation, and chemical vapor deposition (CVD), are used under laboratory conditions (Sharma et al., 2015). At the first stage of growth of so-called vapor - grown carbon fibers, CNTs are synthesized, and during arc discharge, CNTs are obtained in the carbon deposits on the graphite anodes. Under related arc discharge conditions, "graphite whiskers," which are fibrous carbon consisting of a scroll of carbon layers, were collected in 1960 (Inagaki et al., 2014). As a result, CNTs were initially generated using high-temperature techniques such as arc discharge or laser ablation, but CVD is now more widely used because it can be achieved at a lower temperature $\left(<800^{\circ} \mathrm{C}\right)$. Furthermore, the CVD approach allows for precise monitoring of experimental conditions such as CNT direction, alignment, weight, diameter, mass, and purity (Pandey \& Dahiya, 2016; Sharma et al., 2015).

\subsection{ARC DISCHARGE METHOD}

The highest performing nanotubes can be obtained using the arc discharge process, which is also known as plasma-based synthesis method (Kaur et al., 2018). As previously stated, the first CNTs were generated using this method between graphite electrodes (Ferreira et al., 2019). A vacuum chamber was used in this process, and two graphite electrodes with a gap width of 1-2 mm were mounted within the chamber to assist in achieving a steady discharge. The chamber must first be filled with an inert and low-pressure gas such as helium or argon at around 500 torr before a direct current of 50-100 amperes can be transmitted between the two electrodes. The gas inside the chamber would be ionized, converting it to electrons and ions. The creation of hot plasma between the electrodes will occur because of this (Ferreira et al., 2019; Raunika et al., 2017). As a result, graphite will vaporize; some of it will condense on the reaction vessel, while the remainder will condense on the cathode (Kaur et al., 2018). Temperatures as high as $4000-6000 \mathrm{~K}$ will be produced during this operation, triggering sublimation of the carbon precursor at the anode. Meanwhile, the carbon vapors emitted will be deposited on the cathode, which will cool down (Raunika et al., 2017). The inert gas and direct current are two of the most critical parameters in this system for maximizing yield (Mohammad et al., 2013).

Furthermore, both SWCNT and MWCNT can be generated in large quantities (large yield quantity in gram quantities) using this form, and the duration of the produced CNTs is greater than $40 \mu \mathrm{m}$ (Mohammad et al., 2013; Yang, 2015). Additionally, for this method, production of SWCNTs in relatively large amounts requires metals catalysts such as cobalt (Co), nickel (Ni) and yttrium (Y) to be introduced in the anode electrode (Kaur et al., 2018; Raunika et al., 2017). As Ni-Y graphite mixtures are used, high yields of SWCNTs (<90\%) with a diameter of $1.4 \mathrm{~nm}$ have been achieved in recent studies (Rahman et al., 2019). Meanwhile, the production of MWCNTs does not requires any metal catalyst (Ferreira et al., 2019). The schematic diagrams of the arc discharge for CNT synthesis and development as shown in Fig. 5. This process produces tubes of different lengths, which are normally entangled and have a low defect rate, which mean a better high quality (Loos, 2015). The disadvantage of this process is that the samples obtained are in powder form, with the nanotubes twisted into bundles (Saifuddin et al., 2013).

\subsection{LASER ABLATION (LASER VAPORIZATION)}

The CNTs were first synthesized using a laser in 1995, and the pulsed laser vaporization (PLV) technique is used to extract a large variety of carbon allotropes from graphite, one of which is CNTs (Chrzanowska et al., 2015; Ferreira et al., 2019). A laser beam (Yttrium Aluminum Garnet or $\mathrm{CO}_{2}$ laser) was used in this process, and it will be put within a reactor, where it will be focused on the graphite rods. Until beginning the process, argon buffer gas and a catalyst mixture of $\mathrm{Co}$ and $\mathrm{Ni}$ in a 50:50 ratio was passed through the rod at $1200^{\circ} \mathrm{C}$. The metal was added to the process to help catalyze the creation of SWCNTs, but it also produced a slew of other byproducts. As a result of the high temperature of the argon buffer steam, the rod will vaporize. As the vaporization was cooled, it was deposited in the copper collector, and nanotubes were formed (Kaur et al., 2018; Raunika et al., 2017). The schematic diagrams for the laser ablation procedure are shown in Fig. 6. 
One of the benefits of this method is that high-quality SWCNTs with limited defects can be achieved in a reasonably high yield. Since the metallic atoms appear to vaporize when the tube's end is closed, this was possible. SWCNTs generated have excellent structural integrity as well. Furthermore, diameter modulation of the samples can be achieved easily by adjusting the method's parameters, i.e. catalytic metal, flow rate, and temperature (Chrzanowska et al., 2015; Rahman et al., 2019; Raunika et al., 2017). Apart from that, SWCNTs can be synthesized without requiring the production of MWCNTs (Ferreira et al., 2019). However, there are several drawbacks to this approach. The CNTs generated may have some branching and may not be perfectly straight. Despite using higher purity graphite rods and laser forces, the amount of CNTs generated is lower than when the arc discharge approach is used (Rahman et al., 2019).

Typically, a significant amount of SWCNTs can be generated with good crystallization using both arc discharge and laser ablation methods. However, owing to the unique basic equipment requirements and high energy demand, these two strategies are less advantageous than CVD (Saifuddin et al., 2013). In terms of yield and purity, CVD are superior to arc and laser methods. This is because the size of the carbon source, i.e., anode for arc discharge and target for laser ablation, determines the amount of the sample formed in both arc and laser processes. There is also a need for intensive purification of CNTs developed using these two techniques, which led to the production of gas phase methods like CVD (Raval et al., 2018; Wang et al., 2019).

\subsection{CHEMICAL VAPOR DEPOSITION (CVD)}

CVD is showing high potential to be used further as a CNTs processing tool for future industrial applications due to advantages such as relatively low growth temperature, high yields, and high purities with many explicit properties that can be obtained during its manufacture (Hussein \& Abdulrazzak, 2018). While this process was first used in the 1960s and 1970s to produce carbon fibers and carbon nanofibers, it was not until 1996 that it was used on a wide scale for the production and synthesis of CNTs. Strong, liquid, and gaseous precursors were used to aid in the development of CNTs at relatively low temperatures, i.e., 500 to $1000^{\circ} \mathrm{C}$, and at atmospheric pressure. Metal or metal oxide catalyst particles are used as "seeds" to aid in the development of certain precursors (Shah \& Tali, 2016; Vivekanandhan et al., 2017). In addition, the gaseous or volatile carbon compound can decompose with the aid of metallic nanoparticles as a catalyst in this step. The catalyst also serves as a nucleation site for the development of CNTs (Saifuddin et al., 2013). The reaction chamber is filled with a combination of nitrogen, ethylene, and acetylene during the procedure (Kaur et al., 2018).

This approach allows CNTs to expand in a variety of macroscopic morphologies, including powders and films (i.e., thick or thin), as well as various microscopic architectures (i.e., aligned, coiled, intertwined, or straight). The simplicity of the process is due to the use of such precursors, as well as different substrates and catalysts (Vivekanandhan et al., 2017). As a result, producers will get the desired type of CNT. The four key parameters that specify the form of CNTs formed (SWCNT or MWCNT) in this process are the reactor's atmosphere, the source of hydrocarbon, the catalyst, and the growth temperature. MWCNTs are typically formed at lower temperatures (i.e. 600 to $900^{\circ} \mathrm{C}$ ), while SWCNT development occurs at temperatures greater than $900^{\circ} \mathrm{C}$ (Hussein \& Abdulrazzak, 2018). Not just that, but the commodity obtained is purer and has a higher yield. Regardless, defects can be detected in the composition of the samples collected, and these defects are normally in significant numbers (Loos, 2015; Raunika et al., 2017). The general and basic schematic diagrams for the CVD technique are shown in Fig. 7.

\subsubsection{THERMAL CATALYTIC CVD}

Decomposition of hydrocarbons or other carbon feedstock will take place at elevated temperatures ranging from 500 to $1200^{\circ} \mathrm{C}$ in this process. Prior to use, the feed would be dissolved in a steady flow of noble gases in the furnace, which would pass through transition metal catalysts such as iron, nickel, and cobalt, among others. The decomposed carbon would dissolve such metal particles until it reached a point of super saturation. The hydrocarbon is then decomposed and deposited on a substrate, i.e., alumina, glass, or silicon substrate. The carbon precipitate would then form in the shape of fullerene dorms. Depending on the temperature range of the process, different forms of CNT may be produced by using various types of carbon feedstock. Chemical composition and textural properties of the catalyst material(s) used are two parameters that control the length, diameter, orientation, and consistency of produced CNTs. The amounts of defects and the existence of amorphous carbon was also used to test the above properties of the finished product (Raunika et al., 2017; Yang, 2015).

\subsubsection{PLASMA-ENHANCED CVD (PECVD)}

PECVD is a broad concept that encompasses a variety of synthesis methods which may be either direct or remote. Direct PECVD was used to make MWCNT field emitter towers and some SWCNTs, while remote PECVD can be used to develop all types of CNTs (Pandey \& Dahiya, 2016). Instead of using thermal energy, this method uses energy sources that can supply energy for both hydrocarbon decomposition and CNT processing at a low temperature. The plasma energy sources used on the CNT formation are hot filament PECVD, direct current PECVD, radio frequency PECVD, and microwave PECVD. Hydrocarbon gas is used over intermediate metals in an ionized state in this process (Raunika et al., 2017). Furthermore, the reactive species in the plasma system influenced the development of microscopic diameter tubes, which had implications for both diameter regulation and selective etching of metallic SWCNTs (Saifuddin et al., 2013). The PECVD process consists of three major stages: (i) primary reaction takes place between energetic particles and carbon precursor in nonequilibrium plasma which leads to the precursor to be decomposed into carbon atoms and other active radicals; (ii) diffusion of carbon atoms and radicals onto the catalyst surface, as well as secondary reactions between the reactants, and (iii) catalyst interacts with the reactants on its surface, allowing carbon atoms to infiltrate and precipitate, as well as the release of result gases (Ding et al., 2016).

This kind of CVD process has the benefit of producing a high yield of matched CNTs at a lower substrate temperature (Raval et al., 2018). Furthermore, by adding a voltage to the substrate, the volume of supplied ionized carbon species onto the catalyst surface can be tuned. The chirality distribution and growth rate of SWCNTs can be regulated, for example, by adjusting catalyst size and $\mathrm{H}_{2}$ flow rate (Yanase et al., 2019).

\subsubsection{ALCOHOL CVD (ACCVD)}


Since the temperature of the process is relatively low as low as $550^{\circ} \mathrm{C}$, the ACCVD system can produce SWCNTs in large quantities at a low cost. Evaporated methanol and ethanol are applied to zeolite-supported iron and cobalt catalytic metal particles in this process. Alcohol reacting with catalytic metal particles created hydroxyl radicals, which removed carbon atoms with hanging bonds, preventing the formation of high-purity SWCNTs. The produced SWCNTs has diameter of about one nm (Varshney, 2014). The synthesis method for CNTs is compared in Table 2 and Table 3.

Table 2

Summary of the CNT synthesis process (Aqel et al., 2012; Kaur et al., 2018; Saifuddin et al., 2013)

\begin{tabular}{|c|c|c|c|c|}
\hline & Arc discharge & Laser ablation & CVD & References \\
\hline Discovery & $\begin{array}{l}\text { Ebbesen and Ajayan, NEC, Japan } \\
1992\end{array}$ & Smalley, Rice, 1995 & Endo, Shinshu University, Nagano, Japan & $\begin{array}{l}\text { (Ebbesen \& } \\
\text { Ajayan, 1992; } \\
\text { Gupta et al., } \\
\text { 2019; Manawi } \\
\text { et al., 2018) }\end{array}$ \\
\hline \multirow[t]{2}{*}{ Process } & \multirow[t]{2}{*}{$\begin{array}{l}\text { Graphite electrodes (with distance in } \\
\text { between } 1-2 \mathrm{~nm} \text { ) kept in enclosure in } \\
\text { presence of inert gas (e.g., helium, } \\
\text { argon), and direct current of } 50-100 \\
\mathrm{~A} \text { are used }\end{array}$} & $\begin{array}{l}\text { Vaporization of graphite } \\
\text { rods which contain catalyst } \\
\text { material by pulsed or } \\
\text { continuous laser, in a } \\
\text { quartz tube furnace. }\end{array}$ & $\begin{array}{l}\text { Reaction chambers contain mixture of } \\
\text { nitrogen, ethylene, and acetylene. The } \\
\text { temperature of reaction chamber during the } \\
\text { process was } 700-900^{\circ} \mathrm{C} \text { and at } 1 \text { atm } \\
\text { condition. }\end{array}$ & \multirow[t]{2}{*}{$\begin{array}{l}\text { (Gupta et al., } \\
\text { 2019; Kaur et } \\
\text { al., 2018; } \\
\text { Saifuddin et } \\
\text { al., 2013) }\end{array}$} \\
\hline & & $\begin{array}{l}\text { Blast graphite with intense } \\
\text { laser pulses rather than } \\
\text { electricity }\end{array}$ & $\begin{array}{l}\text { Place substrate in oven, heat to high } \\
\text { temperature, and slowly add a carbon- } \\
\text { bearing gas (e.g., methane). As gas } \\
\text { decomposes, it frees up carbon atoms, } \\
\text { which recombine in form of NTs. }\end{array}$ & \\
\hline Conditions & $\begin{array}{l}\text { Inert gas (helium or argon) at low } \\
\text { pressure (between } 50-700 \text { mbar) }\end{array}$ & $\begin{array}{l}\text { Inert gas (helium or argon) } \\
\text { at } 1200^{\circ} \mathrm{C} \text { and pressure } \\
500 \text { Torr }\end{array}$ & $700-900^{\circ} \mathrm{C}$ at $1 \mathrm{~atm}$ & $\begin{array}{l}\text { (Gupta et al., } \\
\text { 2019; Kaur et } \\
\text { al., 2018) }\end{array}$ \\
\hline Typical yield & $32-91 \%$ & Up to $70 \%$ & $20-100 \%$ & $\begin{array}{l}\text { (Kaur et al., } \\
\text { 2018) }\end{array}$ \\
\hline SWCNT & Short tubes with diameter $0.6-1.4 \mathrm{~nm}$ & $\begin{array}{l}\text { Long bundles of tubes (5- } \\
20 \text { microns) with diameter } \\
1-2 \mathrm{~nm} \text { (individual } \\
\text { diameter) }\end{array}$ & $\begin{array}{l}\text { Long tubes with diameter ranging from 0.6- } \\
4 \mathrm{~nm}\end{array}$ & $\begin{array}{l}\text { (Aqel et al., } \\
\text { 2012) }\end{array}$ \\
\hline MWCNT & $\begin{array}{l}\text { Short tubes with inner diameter } 1-3 \\
\text { nm and outer diameter of } \\
\text { approximately } 10 \mathrm{~nm}\end{array}$ & $\begin{array}{l}\text { Not much interest in this } \\
\text { technique as it is too } \\
\text { expensive, but synthesis of } \\
\text { MWCNT is possible }\end{array}$ & $\begin{array}{l}\text { Long tubes with diameter ranging from } 10- \\
240 \mathrm{~nm}\end{array}$ & $\begin{array}{l}\text { (Aqel et al., } \\
\text { 2012) }\end{array}$ \\
\hline Carbon source & Pure graphite & Graphite & $\begin{array}{l}\text { Fossil-based hydrocarbon and botanical } \\
\text { hydrocarbon }\end{array}$ & $\begin{array}{l}\text { (Shah \& Tali, } \\
\text { 2016) }\end{array}$ \\
\hline Cost & High & High & Low & $\begin{array}{l}\text { (Kaur et al., } \\
\text { 2018) }\end{array}$ \\
\hline Advantages & $\begin{array}{l}\text { Simple, inexpensive, high - quality } \\
\text { nanotubes }\end{array}$ & $\begin{array}{l}\text { Relatively high purity, room } \\
\text { - temperature synthesis }\end{array}$ & $\begin{array}{l}\text { Simple, low temperature, high purity, large- } \\
\text { scale production, aligned growth possible } \\
\text { Allows control over the produced CNTs' } \\
\text { morphology and structure }\end{array}$ & $\begin{array}{l}\text { (Ali et al., } \\
\text { 2014; Manawi } \\
\text { et al., 2018) }\end{array}$ \\
\hline \multirow[t]{3}{*}{ Disadvantages } & $\begin{array}{l}\text { Little control over the nanotubes' } \\
\text { orientation and required further } \\
\text { purification due to usage of catalyst }\end{array}$ & $\begin{array}{l}\text { Nanotubes produced are } \\
\text { not perfectly straight and } \\
\text { has branching }\end{array}$ & $\begin{array}{l}\text { Nanotubes produced have more structurally } \\
\text { defects }\end{array}$ & \multirow{3}{*}{$\begin{array}{l}\text { (Ali et al., } \\
\text { 2014; Manaw } \\
\text { et al., 2018; } \\
\text { Rahman et al } \\
\text { 2019) }\end{array}$} \\
\hline & \multirow[t]{2}{*}{$\begin{array}{l}\text { High temperature, and tangled } \\
\text { nanotubes produced }\end{array}$} & $\begin{array}{l}\text { Requires lasers with high } \\
\text { powers and highly pure } \\
\text { graphite rods }\end{array}$ & \multirow{2}{*}{ Synthesized CNTs are usually MWCNTs } & \\
\hline & & $\begin{array}{l}\text { Method limited to the lab } \\
\text { scale; crude product } \\
\text { purification required }\end{array}$ & & \\
\hline
\end{tabular}


Table 3

The comparison of the CNTs' synthesis methods.

\begin{tabular}{|c|c|c|c|c|}
\hline & $\begin{array}{l}\text { Laser } \\
\text { ablation }\end{array}$ & $\begin{array}{l}\text { Arc } \\
\text { discharge }\end{array}$ & CVD & References \\
\hline Reaction temperature $\left({ }^{\circ} \mathrm{C}\right)$ & 3000 & $3000-4000$ & $500-1100$ & (Mubarak et al., 2014) \\
\hline Per unit design cost & High & High & Low & (Rafique \& Iqbal, 2011) \\
\hline Nanotube selectivity & Low & Low & High & $\begin{array}{l}\text { (Malekimoghadam \& Rafiee } \\
\text { 2018) }\end{array}$ \\
\hline $\begin{array}{l}\text { Carbon source/ Raw source } \\
\text { availability }\end{array}$ & Difficult & Difficult & Easy, abundantly available & (Rafique \& lqbal, 2011) \\
\hline Purification of CNT (high impurities) & High & High & Low & (Mubarak et al., 2014) \\
\hline Process nature & Batch & Batch & Continuous & (Hiremath et al., 2016) \\
\hline Process parameter control & Difficult & Difficult & Easy to control & $\begin{array}{l}\text { (Malekimoghadam \& Rafiee } \\
\text { 2018) }\end{array}$ \\
\hline Energy requirement & High & High & Low & (Mubarak et al., 2014) \\
\hline Design of reactor & Difficult & Difficult & $\begin{array}{l}\text { Easy and can be designed as large-scale } \\
\text { process }\end{array}$ & (Rafique \& Iqbal, 2011) \\
\hline Graphitization of nanotube & High & High & Middle & $\begin{array}{l}\text { (Malekimoghadam \& Rafiee } \\
\text { 2018) }\end{array}$ \\
\hline
\end{tabular}

\subsection{Purification Techniques For Cnts}

The form and number of impurities that come with CNTs differ depending on the process used to make them. Carbonaceous materials and metals are the most common impurities found. Aside from that, the as-produced CNT soot contains several impurities. Graphite (wrapped up) tubes, amorphous carbon, metal catalyst, and smaller fullerene are four common impurities that will interact with much of the desired properties of CNTs. Strong oxidation and acidrefluxing processes are the industry's favored purification procedures, but they can influence the tubes' composition. Liquid chromatography, however, is the least preferred solution due to the insoluble nature of CNTs.

In general, CNT purification steps aid in the elimination of amorphous carbon, the enhancement of surface area, the increase or decrease in volume (i.e., mesopore or micropore), and the decomposition of functional groups that obstruct pore entry or the promotion of additional functional groups. The separation techniques can then be separated into two categories: structure-selective separation techniques and size-selective separation techniques (Aqel et al., 2012). These tactics may be used on their own or in combination with others. The latter option, on the other hand, was often used to increase purification while also eliminating other impurities. The common purification methods are mentioned below.

\subsection{OXIDATION TREATMENT}

Gas phase oxidation, liquid phase oxidation (acid treatment), and electrochemical oxidation are the three methods of oxidative treatment. Gases such as air, $\mathrm{O}_{2}, \mathrm{Cl}_{2}, \mathrm{H}_{2} \mathrm{O}$, and others are used in the first form of operation. The tubes are heated at about $330^{\circ} \mathrm{C}$ in either wet air, vacuum, or with other oxidizing agents at a controlled temperature, and for a prolonged period. Carbonaceous impurities are mostly eliminated from CNTs because of this process. Regardless, this procedure influences the tubes because it often exposes the ends of CNTs, slices CNTs, and affects the surface structure of CNTs. Oxygenated functional groups $(-\mathrm{OH},-\mathrm{C}=\mathrm{O}$, and $-\mathrm{COOH})$ were eventually added to CNTs. Since the metal particles could not be separated directly from the CNTs with this treatment alone, additional acid treatment was needed. The liquid phase oxidation, also known as acid treatment, is the next type. Metal catalyst and some fullerenes will be eliminated in this treatment. Of the various acids, $\mathrm{HNO}_{3}$ is the only one that does not degrade the tubes until the tubes are left inside the $\mathrm{HNO}_{3}$ for a prolonged period (usually $>16 \mathrm{~h}$ ). CNTs will remain suspended until treatment, while the metal catalyst will be solvated. The electrochemical oxidation is the final form of oxidation. This method works well for CNTs that have few defects, so they are more resistant to electrochemical oxidation. It may also be used to purify CNT arrays without losing their orientation. The CNTs electrode is first immersed in a $0.2 \mathrm{M} \mathrm{HNO}_{3}$ solution or a $0.2 \mathrm{M} \mathrm{HCl} \mathrm{solution} \mathrm{(i.e.,} \mathrm{purge} \mathrm{with} \mathrm{N}_{2}$ for 20 minutes before usage). The capacity was then cycled between +1.00 and $+2.00 \mathrm{~V}$ at a scan rate of $50 \mathrm{mVs}^{-1}$ (Saifuddin et al., 2013 ). Metal contents, oxidation time, atmosphere, oxidizing agents, and temperature were all factors that influenced the efficiency and yield of the procedures (Aqel et al., 2012).

\subsection{ULTRASONICATION}

The isolation of particles caused by ultrasonic vibrations is the basis for this technique (Aqel et al., 2012). The suspension of CNTs can be performed in either pure water, toluene, or in an acid solution, and then sonicated for 5 to 30 minutes. Tubes will be isolated from attached particles during sonication, resulting in nanotube dispersion and other particles for improved centrifugation. The amount of surfactant, solvent, and reagent used in the process has a significant impact on particle separation. Meanwhile, the solvent used had a significant impact on the consistency of the dispersed tubes in the device (Saifuddin et al., 2013). If CNTs are still bound to the metal, they are more soluble in weak solvents. Monodisperse ions, on the other hand, are relatively soluble in certain solvents, such as alcohols (Aqel et al., 2012).

\subsection{MAGNETIC PURIFICATION}


This process mechanically separates ferromagnetic (i.e., catalytic) particles from their graphitic shells. To extract the ferromagnetic particles, inorganic particles (mostly $\mathrm{ZrO}_{2}$ or $\mathrm{CaCO}_{3}$ ) were combined with $\mathrm{CNT}$ suspension in an ultrasonic bath. The ions would then be captured using permanent magnetic poles. After that, a chemical treatment would be applied to achieve a high purity CNT. The advantages of this approach include the ability to produce laboratory-scale quantities of CNTs without the use of large equipment. The result is also free of magnetic impurities (Aqel et al., 2012).

\subsection{MICRO-FILTRATION}

Micro-filtration technique is usually used together with the oxidation process. Nanoparticles such as catalyst metal, fullerenes, and carbon nanoparticles migrate through the filter using this process, while CNTs and a small amount of carbon nanoparticles remain stuck within the filter (Aqel et al., 2012). Although carbon nanotubes are not soluble in simple solutions, their acid decomposition products are. These products can then be isolated, typically under vacuum, using a simple $\mathrm{pH} 11$ solution and a 3-5 $\mu \mathrm{m}$ filter (Saifuddin et al., 2013).

\subsection{CENTRIFUGATION}

The impure CNTs will be centrifuged for 30 minutes to 3 hours at $7000 \mathrm{~g}$. The supernatant would be withdrawn after one run, and the goods would be centrifuged again. Impurities such as nanospheres, metal nanoparticles, and other carbon particles are extracted using this process. The yield of nanotubes would be limited if the centrifugation were performed several times (Saifuddin et al., 2013).

\subsection{MICROWAVE PURIFICATION}

The CNTs will be diluted in $\mathrm{HNO}_{3}$ solution after the sonication phase in this method (any other types of acid are also acceptable to be used). The CNTs will then be microwaved at $100-200 \mathrm{~W}$ for over 30 minutes at a temperature of $\sim 200^{\circ} \mathrm{C}$. After that, the microwave's temperature will be maintained at $200^{\circ} \mathrm{C}$ for 30 to 90 minutes. Impurities like amorphous carbon, metals, and other nanoparticles will be eliminated as a result (Saifuddin et al., 2013).

When various purification methods are used, different findings are obtained. When choosing purification methods, it is critical that the procedure only removes carbon impurities and metals, with no modifications to the CNTs, especially on the structural surfaces (Aqel et al., 2012).

\section{Application Of Cnt}

CNTs had a wide variety of possible applications due to their unusual anisotropic and stronger molecular interaction properties, and had piqued the interest of several different fields and industries (Shahidi \& Moazzenchi, 2018). These applications are systematically mentioned here.

\subsection{MEDICAL AND BIOMEDICAL FIELDS}

CNTs are a promising commodity in the biomedical field because they have several distinct characteristics, including an excellent structure that enhances the remarkable combination of mechanical, electrical, and optical properties. CNTs are used in biomedical applications such as biomolecule transfer, gene delivery to cells or organs, and tissue regeneration. CNTs are naturally hydrophobic materials, but they can be functionalized to accommodate specific applications. CNTs' appealing properties are what have led to their widespread use, i.e. (i) because of their hollowness and wide surface area, they are ideal for drug distribution, (ii) due to their hydrophobicity, they have increased functionality in the delivery of biomolecules, and (iii) for the combined use of contrast agent, photodynamic therapy, and photoacoustic imaging, great optical properties are needed (Alshehri et al., 2016; Lamberti et al., 2015; Prajapati et al., 2020).

Drug and gene distribution are one of the medicinal systems that uses CNTs, and Fig. 8 shows how CNTs are currently used as drug carriers. With the 12-hour delivery of dextroamphetamine in the 1950s, Smith Kline and French pioneered the idea of drug delivery release. Since then, three waves of drug delivery systems have emerged. Cancer therapy is one of the most common uses of carbon nanotubes in drug delivery systems. The CNT-based anticancer drugs have received a lot of attention, and their distribution is dependent on two strategies. First, targeted distribution can be accomplished by functionalization of tumor receptors. The second technique involves releasing drugs in a regulated atmosphere that mimics tumor conditions, such as a lower pH. CNTs can administer a limited number of medications to the same tumor site using this technique. As a result, device toxicity will be decreased or eliminated, and the negative side effects of standard anticancer medications will be reduced as well. CNT-based medications are also used in other forms, such as a CNT-based carrier for antigen immunization. SWCNTs were used as the carrier instruments for this CNT-based vaccine, and they were effective in achieving successful tumor antigens. CNTs can then be filled with a number of biomolecules such as siRNAs, genomes, and DNA, making them an important method for gene silencing and distribution. CNTs were used to develop an effective and specific nonviral gene delivery mechanism. For example, CNTs were functionalized with poly(lactic-co-glycolic) (PLFA) to deliver the proapoptotic protein caspase-3 (CP3) into osteocarcinoma cells. CNTs were also used to inject the GFP gene into the cultured cell lines. Furthermore, SWCNTs were used to not only transport DNA molecules, but also to prevent certain molecules from being digested by the nucleases present in the cytoplasm (Alshehri et al., 2016; Menezes et al., 2019).

The other use will be in biomedical imaging, which is the use of high-resolution imaging techniques to image the actions of cells, tissues, organs, or the whole body. CNTs are used to study and enhance imaging functionalities as well as their reaction to their surroundings. Photoacoustic imaging (PAI) is one form of biomedical imaging. PAl, which enables photographs of deeper tissues to be seen by using various contrast agents to target particular areas, is ideal to be done on CNTs because they have a high absorbance and contain impurities in the form of metallic nanoparticles (Alshehri et al., 2016). MWNTs and SWNTs are used as photothermal agents in this imaging since they both have a good near-infrared field (NIR). Furthermore, due to their firm NIR absorbency, NTs are well-suited to serve as contrast-mediums for PAI. SWNTs also have the most signal as compared to other carbon materials such as fullerenes and graphitic microparticles, making them suitable contrast-mediums for PAI. CNTs may also be mixed with other absorptivity nanomaterials to boost or 
multiplex PAl, giving CNTs a universal nanoplatform. Fluorescence imaging and Raman imaging are two other methods of biomedical imaging (Chen et al., 2017).

CNTs in composites may often be used to regenerate and engineer bone tissue, and they are classified as biomimetic nanocomposites of collagen fibers at the cell hierarchy stage. CNTs have a beneficial effect on cell adhesion by stimulating cell adhesion, as well as cell morphology modulation and stem cell differentiation acceleration due to their preferential affinity for cell binding, which facilitates new bone development when osteoblast differentiation and apatite mineralization are triggered. Conjugating moieties such as aptamers, peptides, and small molecules may be used to functionalize CNTs for use in diseased bone tissue aggregation, targeting the pathological site, and effectively delivering specific therapeutic agents (Pei et al., 2019).

CNTs can also be used for biosensing because of their wide basic surface area, which allows for the immobilization of certain functional groups, such as receptor moieties. The different forms of CNT-based biosensors are shown in Fig. 9. Biosensors are one of the most important methods for biological identification of bioactive molecules. The use of carbon nanotubes in biosensors has allowed the identification of biological species at lower concentrations, transforming the biosensor into an ultrasensitive biosensor. Nanosized biosensors are used to track a variety of body conditions. For diabetics, for example, a glucose biosensor is critical for monitoring glucose levels. Immunosensors, virus sensors, and protein sensors are some other examples. Enzyme biosensors, such as the tyrosinase biosensor, are also common. The electrocatalytic activity of MWCNTs was used in this biosensor to increase the reaction signal, thus improving the shelf life and activity. (Raphey et al., 2019; Sireesha et al., 2018).

\subsection{FABRIC AND TEXTILE INDUSTRIES}

Since CNT fabric is a nonwoven cloth, it is easier to produce than woven or knitted fabrics. Weaving CNT yarn also allows for the development of stronger fabrics. However, yarn is more expensive than sheet, and the rate will rise even more after the yarn is woven. Composite fabrics, electrical power conductors, technical textiles, and other uses for CNT cloth and yarn are among the possibilities (Chitranshi et al., 2019).

CNTs are used in the production of conductive textiles, for example. Since carbon nanotubes are made up entirely of carbon atoms, they have a broad variety of conductivities, ranging from insulator to conductor. Because of their high surface area, light weight, and excellent electric and mechanical properties, CNTs have recently been used as an electronic feature in the manufacture of wearable electronic textiles. In addition, several researchers have focused on the integration of carbon nanotubes in conductive textiles in recent years. MWCNT, for example, was used as a covering in the alteration of PET fabrics in 2016. Nanotubes are coated on the surface of fibers using the padding process, which involves suspending nanotubes in water. As a result of the procedure, the materials were not only stable and easy to mold, but they also had a long-lasting network conductivity. Another case is Lin et al., who used the melt extrusion process to cover polyester yarns with polypropylene and MWCNT in 2016. They calculated that using 8 wt\% MWCNT for the coating would result in an electrical conductivity of $0.8862 \mathrm{~S} / \mathrm{cm}$ (Shahidi \& Moazzenchi, 2018).

Furthermore, the development of composite textiles with CNTs has appeared at the forefront of practical and smart textiles science. The capabilities of practical textiles can be extended as well as new applications for the consumer industry by adding CNT products. With the use of carbon nanotubes, the textile's efficiency value improves. For example, better filtration capability for waterborne and airborne pollutants, electrical conductivity that can accommodate interconnected electronic circuits, and the ability to harness and produce electricity are all possibilities. Textiles impregnated with CNT and made of CNT are very light and have a low strength compared to other fabrics (Chitranshi et al., 2019).

CNT's special properties, such as ultra-light weight, high aspect ratio, high electrical and thermal conductivity, and high mechanical efficiency, have made them an appealing nanomaterial for wearable sensor fabrication. CNT sensors are not only practical and scalable, but they are also energy efficient. These wearable devices are used in robots like surgical instruments, environmental sensors, and motion detectors for sensing purposes. Furthermore, owing to their peculiar properties, it can be used as a gas sensor, and can be used alone or in conjunction with other materials. The lightweight wearable sensor was created by doping the sensor with multi-walled CNTs, and it can be used to track medical physiology, orientation, and climate. Following that, CNT was used in the manufacture of fire-retardant textiles. Flame resistance and thermal anisotropy are two of CNT's characteristics. As a result, heat can be conducted around the axis of a single CNT tube, as the tube's diameter is comparatively insulating. Furthermore, owing to the anisotropic behavior of the nanotubes, heat can be transferred through the aligned layer and partly diverted to a cold reservoir in the textile that has been infused with CNT. These properties are particularly beneficial to firefighters because they help shield them from fatigue and heat stress (Shahidi \& Moazzenchi, 2018).

The incorporation of carbon nanotubes in textiles will functionalize traditional fabrics without affecting the fabric's fundamental properties such as softness and flexibility. As a result, CNT can be seamlessly incorporated into the fabric scheme (Chitranshi et al., 2019).

\subsection{WASTEWATER TREATMENT}

CNTs can be a promising anode material for microbial fuel cells (MFC) because of their high conductivity and high surface-to-volume ratio. Microbial fuel cells are one of the most important, environmentally sustainable methods for wastewater treatment. Direct application of CNT, on the other hand, may induce cellular toxicity. As a result, CNTs can be used as an anode medium by coating them with conductive polymers including polyaniline and polypyrrole. The electrode specific surface area can be increased by adapting CNTs in this process, thus improving charge transfer efficiency. Following that, a threedimensional structure was obtained by evenly covering the CNT on a macroscale porous substrate, which demonstrates close contact with the microbial biofilm. The electron transfer from the exoelectrogens to the electrode surface had been aided by this. As a result, the charge transfer resistance was significantly reduced, resulting in improved MFC efficiency. For MFC cathodes, oxygen was commonly used to accept electrons. However, oxygen had a weak reduction reaction under typical operating conditions, affecting MFC efficiency. Consequently, bacteria are used as a catalyst to strengthen cathode reduction reactions. CNTs made strong interaction with the redox active core of redox proteins within certain bacteria due to their size and shape. As a result, the CNTbased cathode can assist electron transport, enhancing the oxygen reduction reaction (Attar \& Ranveer, 2015).

Page $9 / 22$ 
CNT are also used for water filtration as anti-microbial materials. Strong antimicrobial activity was shown by CNTs especially SWCNTs. High bacterial retention was shown by SWCNT filter, while high viral removal is exhibited by MWCNT at low pressure, and both are done through size exclusion effect. Bacterial inactivation and viral preservation at low pressure can be accomplished by integrating all types of nanotubes as a hybrid filter. (X. Liu et al., 2013). CNTs are also used to isolate endocrine disrupting compounds (EDCs) and pharmaceuticals and personal care products (PPCPs) from wastewater effluents and surface water sources. When SWCNT and MWCNT are used in membrane filters, they can potentially remove a high percentage of PPCPs (10-95\%) and EDCs (60.4-95.2\%) (Kurwadkar et al., 2019). Meanwhile, magnetic MWCNTs have a removal efficiency of $178.57 \mathrm{mg} / \mathrm{g}$ when used to remove methylene blue dye from wastewater (Gopinath et al., 2020).

Aside from that, direct contact membrane distillation (DCMD) treats water with a bucky paper CNT membrane, which has excellent properties such as high thermal conductivity, high porosity, and hydrophobicity. When a bucky-paper CNT membrane was used to desalinate seawater using DCMD, about $99 \%$ of the salt was rejected. The composite CNT membrane, with a permeability of $3.310^{-12} \mathrm{~kg} /(\mathrm{m} . \mathrm{s} . \mathrm{Pa})$ and a lifetime of continuous testing of up to 39 hours, shows an average of $95 \%$ salt rejection. Apart from increased salt rejection, CNTs have several appealing properties, including thermal and mechanical stability, surface hydrophilicity, antimicrobial, and antifouling properties (Ullah, 2018).

\subsection{ENERGY STORAGE APPLICATION}

Solar energy is an ideal option for the rising energy market since it is a plentiful and renewable source of energy. In addition, cost-effective and reliable solutions for the renewable generation and storage of electrical energy, such as for handheld devices and transportation, are in high demand. Carbon-based photovoltaic cells (PVCs) are claimed to be a fantastic new concept for capturing solar energy and converting it into electrified energy. CNTs are p-type semiconductors of incredible mobility, and organic photovoltaic devices are made by mixing $\mathrm{CNTs}_{\text {like }} \mathrm{C}_{60}$ with electron donors in conjugated polymers. CNTs are also used in the manufacture of ultracapacitors or electrochemical double-layer capacitors (EDLCs). The ultracapacitor's properties have been improved by using electrodes made of CNTs that are vertically aligned. The power density of ultracapacitors is four times that of batteries, with an energy density of around $60 \mathrm{~W} / \mathrm{kg}$ and a lifetime of more than 300,000 cycles. The excellent conductivity and surface area of CNTs allow for these changes (Rahman et al., 2019).

Lithium-ion batteries (LIBs) have a wide range of applications, including handheld mobile devices, hybrid motors, and other rechargeable battery systems, and have the higher energy efficiency than other rechargeable battery technologies. Many attempts have been made to produce LIB nanostructured electrodes that are environmentally friendly, highly durable, thinner, and have a greater storage space. Because of their unusual 1D tabular composition, large surface area, enhanced chirality, and high thermal/electric conductivities, CNTs are considered an excellent additive material for LIBs electrodes. Additionally, bulk CNT sponges were used in the manufacture of 3D porous electrodes for LIBs because CNT sponges have a high porosity and mechanical stability. Figure 10 depicted the various methods by which LIBs implement CNTs (Kumar et al., 2017; Lin et al., 2016). Due to the cylindrical shape of carbon nanotubes and their nanosized properties, different hydrogen storage capacities can be reached in different carbon nanostructures, as mentioned in Table 4.

Table 4

Hydrogen storage capacities in CNTs.

\begin{tabular}{|llll|}
\hline Material & Discharge capacity $(\mathrm{mAh} / \mathbf{g})$ & Stored hydrogen (wt.\%) & References \\
\hline SWCNT & 110 & 0.39 & (Nützenadel et al., 1999) \\
\hline Purified SWCNT & 800 & 2.9 & (Rajalakshmi et al., 2000) \\
\hline MWCNT & 297 & 1.051 & (Gao et al., 2001) \\
\hline SWCNT & $<141$ & $<0.5$ & (Jafari, 2018) \\
\hline Aligned SWCNT & 503 & 1.84 & (G. P. Dai et al., 2002) \\
\hline
\end{tabular}

\subsection{STRUCTURAL REINFORCEMENT}

CNTs are an ideal material for load-bearing reinforcement in composites and structural applications ranging from casual things like clothing to military jackets and space elevators, due to their mechanical properties. CNTs are used as composite filler in structures such as tennis rackets, aircraft body parts, and even spacecraft. Polymers and epoxy resins are also used in conjunction with CNTs to improve properties such as durability, strength, and hardness (Jafari, 2018).

In composites, CNT is a promising filler material whereby when coupled with very large interfacial contact region, will exhibited excellent electrical, thermal, and mechanical properties. CNT-reinforced polymer composites have drawn a lot of interest for industrial applications like electronics, energy storage systems, and vehicles because of their compatibility with CNT. Table 5 shows some of the applications for polymer/CNT composites. Apart from that, CNTepoxy composites are widely used in commercial applications such as sporting equipment (i.e., badminton rackets, golf sticks, ski poles, and so on), electronic packaging, and aircraft. Epoxy composites are widely used in the aircraft and aerospace industries due to their high temperature tolerance and high strength-to-weight ratio. The mechanical efficiency of the composites can be increased further by using CNTs as epoxy fillers (Kausar et al., 2016; Mittal et al., 2015). 
Table 5

Polymer/CNT composites application.

\begin{tabular}{|c|c|c|c|}
\hline $\begin{array}{l}\text { Nanotube } \\
\text { type }\end{array}$ & Polymer type & Applications & References \\
\hline MWCNT & Polyethylene & $\begin{array}{l}\text { Automotive external body components, hot melt adhesives, yarn, } \\
\text { and conductive plastic for surface resistivity. }\end{array}$ & $\begin{array}{l}\text { (Kingston et } \\
\text { al., 2014) }\end{array}$ \\
\hline $\begin{array}{l}\text { SWCNT, } \\
\text { MWCNT }\end{array}$ & Polyamide & Electrostatic discharge, electronics and industrial, automotive & $\begin{array}{l}\text { (Kingston et } \\
\text { al., 2014) }\end{array}$ \\
\hline $\begin{array}{l}\text { SWCNT, } \\
\text { MWCNT }\end{array}$ & Polyurethane & Flame retardant, used in wind turbine blade & $\begin{array}{l}\text { (Kingston et } \\
\text { al., 2014) }\end{array}$ \\
\hline MWCNT & $\begin{array}{l}\text { Polyaniline (PANI), Polypyrrole (PP) and Poly-(3,4- } \\
\text { ethylenedioxythiophene) (PEDOT) }\end{array}$ & Supercapacitor electrode materials & $\begin{array}{l}\text { (Frackowiak } \\
\text { et al., 2006) }\end{array}$ \\
\hline MWCNT & $\begin{array}{l}\text { Poly (vinyl alcohol), poly (2-acrylamido-2-methyl-1- } \\
\text { propane sulfonic acid) }\end{array}$ & Sensors and actuators for biomedical applications & $\begin{array}{l}\text { (C. A. Dai et } \\
\text { al., 2009) }\end{array}$ \\
\hline SWCNT & Poly (4-methyl-1-pentene) & Space vehicles, space stations, biomedical art & $\begin{array}{l}\text { (Nurazzi et al., } \\
\text { 2021) }\end{array}$ \\
\hline SWCNT & Poly (methyl methacrylate) & Biocatalytic films & $\begin{array}{l}\text { (Rege et al., } \\
2003)\end{array}$ \\
\hline
\end{tabular}

\section{Toxicity Of Cnt}

Despite a variety of appealing properties and being commonly used in a variety of fields and markets, CNT toxicity remains a major concern. Measurements of cell viability, cell inflammation, and reactive oxygen species (ROS) activity are used to uncover the mechanisms of CNT toxicity. The toxicological effects of commercial and acid purified MWCNTs and SWCNTs have been studied, and certain types of CNTs have a major impact on toxicity levels. According to the findings, the ROS level of commercial CNTs is rising, resulting in increased oxidative stress and a decrease in mitochondrial membrane potential. MWCNTs also demonstrated some toxicity due to metal impurities at high concentrations (Costa et al., 2016; Mamidi, 2019).

Furthermore, many physicochemical factors influence CNTs' biological reactivity and toxicity, including processing process, length, diameter, surface-tovolume ratio, form, concentration, dispersibility in solution, aspect ratio, degree of oxidation, structure, functional group(s), existence of catalyst, dose applied, and the nanomaterials' chemical functionalization (Alshehri et al., 2016; Lanone et al., 2013). Aside from that, the period of exposure and the surfactant used to spread the nanotubes have all been linked to the toxicity of CNTs (Francis \& Devasena, 2018). As a result, several experiments on the toxicity of CNTs, both in vitro and in vivo, have been conducted. Figure 11 depicted the CNTs' toxicity outlook, while Fig. 12 depicted the order in which inflammations would occur. Aside from that, Table 7 compares the negative effects of SWCNTs to the negative effects that may result from heavy use of MWCNTs.

Table 6

The adverse effects of SWCNTs in comparison to the adverse effects that might occurs from intensive usage of MWCNTs.

SWCNT MWCNT

Induces malignancy in stem cells by chronic exposure to CNTs (Jafar et al., 2016)

Differences in cytotoxicity, genotoxic, and inflammatory response of bronchial and alveolar human lung epithelial cells (Jafar et al., 2016)

Inflammatory response of immortalized and primary human

lung epithelial cells (Jafar et al., 2016)

Severe fibrotic peritoneal adhesions, fibrotic peritoneal thickening, and a high incidence of macroscopic peritoneal tumors (Takagi et al., 2008)

In vitro inhibition of HEK 293 cell proliferation (Cui et al., In vitro induce cell cycle arrest and increase apoptosis/ necrosis of human skin 2005) fibroblast (Z. Liu et al., 2009)

\subsection{CYTOTOXIC EFFECTS}

The CNTs entered the body via the lipid bilayer membrane of the cell, causing oxidative stress, inflammation, and cytotoxicity. The foreign body response (FBR) is produced and chemicals are released to eliminate CNTs from the cells as CNTs are behaving as foreign body to the cells. Cellular toxicity could also be caused by the development of free radicals, which contributes to oxidative stress. Figure 13 shows some of the other ways CNTs have induced cellular toxicity (Mohanta et al., 2019).

Cytotoxicity was caused by a number of factors, including the volume and form of metal impurities, the length and type of carbon nanotubes, the presence of surface functionalization and the type of surface functionalization, and the presence of a dispersant or surfactant in the dispersant solution (Alshehri et al., 2016). The cytotoxicity of CNTs are also affected by physiochemical factors such as the cellular uptake, internalization, phagocytosis and also their clearance from body (Manke et al., 2013). Because of their fibrous form, toxins from synthesis, and diameter, CNTs are more harmful to cells than other carbon allotropes. Uncontrolled exposure to CNTs can cause cell damage such as inflammation, granuloma formation, oxidative stress, apoptosis, changes in cell morphology, and mitochondrial dysfunction (Menezes et al., 2019). CNTs have been documented to infiltrate the lung and stay in the tissues through mechanisms similar to those used by other fibrous particles such as asbestos (Jafar et al., 2016).

A comparison of cytotoxic influence, cell viability, and intracellular aggregation of nanoparticles between titanium oxide nanoparticles and MWCNTs onto A549 human pneumocytes is also being performed. Both materials will penetrate cells and then be dispersed in the cytoplasm, according to the findings of 
the analysis. Metal oxide nanoparticles, on the other hand, are less harmful than carbon nanotubes. CNTs are also documented to promote immunemediated cytotoxicity against different human cells at low concentrations $(0.001-0.1 \mathrm{mg} / \mathrm{ml})$. The secretion of cytokines can increase even at low CNT concentrations, signaling lymphocyte activation while also upregulating NF-kB expression in immune cells. As a result, there would be indirect cytotoxicity (Francis \& Devasena, 2018).

\subsection{PULMONARY TOXICITY}

Nanotubes can reach the human body through a variety of pathways, and many innovative goods today use CNTs in their manufacturing. Nanotubes, for example, may reach the human body via dermal and gastrointestinal routes. One of the ways for CNTs to reach the body is through the lungs, which can result in lung inflammation, granuloma, and fibrosis (Francis \& Devasena, 2018; Prajapati et al., 2020). The sensitivity of employees and customers to CNTs during processing, transportation, storage, and disposal is also a major concern (Menezes et al., 2019). This is because CNTs may penetrate the workers' respiratory airways during the manufacturing process, accumulating in the lungs. Nanotubes are also used as fillers in food packaging. Since such nanotubes will enter the stomach and intestines, they could be dangerous to users. Chronic inflammatory reactions, pleural lesions, peribronchial inflammation, and other adverse respiratory symptoms will then arise (Francis \& Devasena, 2018; Lamberti et al., 2015). Physiochemical properties such as functionalization, particle size, and dispersion all played a role in pulmonary toxicity after CNTs were inhaled. Meanwhile, as depicted in Fig. 14, CNT-induced pulmonary toxicity in the pulmonary organs is also reported (Mohanta et al., 2019).

Many researches (both in vivo and in vitro studies) have shown that SWCNTs and MWCNTs cause acute and chronic inflammatory responses, as well as granuloma (Narei et al., 2018). Highly scattered MWCNTs can cause pulmonary lesions depending on the route of administration and dose. In this research, MWCNTs were administered to animals by two different routes: intratracheal instillation and inhalation. Only animals exposed with MWCNTs by intratracheal instillation formed granulomatous lesions or collagen depositions, according to the findings (Francis \& Devasena, 2018). In addition, pulmonary inflammation was observed when SWCNTs or MWCNTs were administered intravenously, as shown by improvements in cellularity and enzyme activities in bronchoalveolar lavage fluid (BALF). Inflammation was linked to macrophage invasion, epithelioid granulomas, and fibrotic modifications in mice and rats (Ma-Hock et al., 2013).

The effects of MWCNTs in rats were also studied after a single dose accompanied by intermittent sacrificing. Even a single exposure to the nanotubes causes inflammation, epithelial cell membrane disruption, and cell lysis, according to the researchers. In this process TNF-a, IL-4, LDH, WBC count, and ALP activity (which function as conforming markers) are found to increase, and thus confirmed the above findings (Francis \& Devasena, 2018). CNTs have a substantial impact on pulmonary function, as seen by an increase in expiratory duration, a decline in bacterial clearance activity, and a reduction in lung compliance. In addition, ovalbumin-induced allergic airway inflammation in vivo is aggravated by both SWCNT and MWCNT (Manke et al., 2014).

\subsection{CARDIOVASCULAR EFFECTS}

Cardiovascular toxicity has been caused by the association of carbon nanotubes with heart muscle cells. The association causes a variety of problems, including cardiac injury, which causes cell proliferation, muscle damage, blood flow obstruction, and vascular atherosclerosis. The main contributors to cardiovascular toxicity are oxidative stress and inflammation, all of which have been established through numerous laboratory studies (Mohanta et al., 2019). The major effect of CNT on the heart is hemolysis and blood clotting (Prajapati et al., 2020).

CNT toxicity causes acute pulmonary inflammation and chronic responses, according to some animal studies. As a result of these findings, it is recommended that CNT toxicity be evaluated as a possible cardiovascular risk factor. According to a study, CNT-induced lung inflammation triggered inflammatory mediators, which then stimulated blood cells, causing cardiovascular side effects. Furthermore, CNTs can serve as predisposing factors for atherogenesis, i.e., the development of atherosclerotic plaque in the arteries (Francis \& Devasena, 2018). Aside from that, the influence of MWCNTs on blood pressure and heart function was studied by inhaling MWCNTs at a concentration of $5 \mathrm{mg} / \mathrm{m}^{3}$ for 5 hours in Sprague-Dawley rats. Owing to improvements in the sympathetic and parasympathetic nervous systems, there is a substantial rise in both systolic and diastolic blood pressure in freely travelling rats, however a reduction in the heart (Prajapati et al., 2020). These specifically demonstrated that the concentration of CNTs in cardiac muscle vascular tissues induced an increase in oxidative stress and inflammation, resulting in cardiovascular organ toxicity (Mohanta et al., 2019).

\subsection{REPRODUCTIVE AND DEVELOPMENT TOXICITY}

Various experiments have shown the dangers of CNTs to animals' reproductive systems and offspring production. According to the findings, low doses of functionalized CNTs (10 ng/mouse) are sufficient to initiate and increase resorptions and fetal malformations in mice. MWCNTs are also said to cause reproductive toxicity in mice when they penetrate the blood-testis barrier at a high concentration of $5 \mathrm{mg} / \mathrm{kg}$ injections through tail vein (Francis \& Devasena, 2018; Prajapati et al., 2020).

Following that, the effects of functionalized carbon nanotubes on reproduction and growth in Drosophila melanogaster and CD-1 mice are assessed. When fetuses are exposed to $10 \mathrm{mg} / \mathrm{kg}$ fCNTs, the proportion of resorptions, gross morphological defects, and skeletal anomalies produced is moderately higher. External anomalies included open eyelids in seven of the fetuses, leg structure abnormalities in three fetuses, and tail structure abnormalities in two fetuses. In addition, as comparison to controls, skeletal examination revealed a higher number of fetuses with reduced phalange ossification on the pectoral and pelvic arms, cervical vertebra defects (specifically C1 and C2), and variable sternebrae ossification. The nanoparticles have had an impact on the reproduction of male offspring when pregnant female mice were exposed to them (Francis \& Devasena, 2018).

The embryolethal and teratogenic effects of administering some pristine and functionalized SWCNTs to mice via intravenous injection and oral gavage were discovered. Apart from that, SWCNTs can cause an increase in ROS production, which is linked to toxicity in development due to placental effects. The

Page $12 / 22$ 
placentas of malformed fetuses have vascular disruption in the labyrinth layer. ROS were increased in the malformed fetuses and their placentas after being induced with uo-SWCNTs, but not in maternal tissues. In addition, when double walled CNTs and MWCNTs are combined, hatching is delayed (Ema et al., 2015).

Long-term MWCNT exposure to $X$. tropicalis, a model aquatic species, was shown to have developmental and reproductive toxicity, including reduced growth rate, as well as effects on the testis, ovaries, and fat, with negligible effects on the heart and liver. With the presence of MWCNTs, the number of spermatogonia or oocytes decreases, while the formation of pulmonary empty cannons increases. When marine animals are exposed to MWCNTs suspension for a long time, either by respiration or oral intake (discharge of MWCNTs in aquatic environment), the possible reproductive toxicity is shown by a reduction in fertilization and survival rates of embryos (Zhao et al., 2020). As a result, further research into nanomaterials' long-term and early-life exposure, as well as their toxicity to reproductive and developmental systems, is needed to reduce the risks of reproductive toxicity.

\subsection{Conclusion}

This review critically discussed the structure of both type of CNTs and their synthesis, purification as well as massive application. Several harmful disadvantages of CNTs, are reported in this study to consider for future exploration. The application of CNTs based composites and CNTs itself are focused on the area of medical and biomedical fields along with their structure, classification, preparation and related properties. Moreover, the toxicity and biosafety of CNTs on the human body are also reported in this review article.

\section{Declarations}

\section{ACKNOWLEDGEMENT}

The authors are grateful for the support of the Universiti Malaysia Sarawak in Kota Samarahan, Sarawak, Malaysia (UNIMAS).

Competing interests: The authors declare no competing interests.

\section{References}

1. Ali E, Hadis D, Hamzeh K, Mohammad K, Nosratollah Z, Abolfazl A, Mozhgan A, Younes H, Woo JS (2014) Carbon nanotubes: properties, synthesis, purification, and medical applications. Nanoscale Research Letters 9(1):393. https://doi.org/10.1186/1556-276X-9-393

2. Alshehri R, llyas AM, Hasan A, Arnaout A, Ahmed F, Memic A (2016) Carbon Nanotubes in Biomedical Applications: Factors, Mechanisms, and Remedies of Toxicity. Journal of Medicinal Chemistry 59(18):8149-8167. https://doi.org/10.1021/acs.jmedchem.5b01770

3. Aqel A, El-Nour KMMA, Ammar RAA, Al-Warthan A (2012) Carbon nanotubes, science and technology part (I) structure, synthesis and characterisation. Arabian Journal of Chemistry 5(1):1-23. https://doi.org/10.1016/j.arabjc.2010.08.022

4. Attar S, Ranveer A (2015) Carbon Nanotubes and Its Environmental Applications. Journal of Environmental Science Computer Science Engineering Technology 4(2):304-311. https://www.researchgate.net/publication/278686227_Carbon_Nanotubes_and_Its_Environmental_Applications

5. Bera B (2017) A Review on Polymer, Graphene and Carbon Nanotube: Properties, Synthesis and Applications. Imperial Journal of Interdisciplinary Research (IJIR) 3(10):61-70.

https://www.researchgate.net/publication/330998898_A_Review_on_Polymer_Graphene_and_Carbon_Nanotube_Properties_Synthesis_and_Applications

6. Chen Z, Zhang A, Wang X, Zhu J, Fan Y, Yu H, Yang Z (2017) The Advances of Carbon Nanotubes in Cancer Diagnostics and Therapeutics. Journal of Nanomaterials. 2017,3418932, 1-14. https://doi.org/10.1155/2017/3418932

7. Chitranshi M, Chauhan D, Kubley A, Pujari A, Xu C, Chen D, Chaudhary S, Hou G, Bell G, Brandewie B, Kaneria R, Hudepohl R, Schulz MJ (2019) Pioneering carbon nanotube textile engineering \& fashion technology. Journal of Textile Engineering Fashion Technology 5(2):89-92.

https://doi.org/10.15406/jteft.2019.05.00187

8. Chrzanowska J, Hoffman J, Małolepszy A, Mazurkiewicz M, Kowalewski TA, Szymanski Z, Stobinski L (2015) Synthesis of carbon nanotubes by the laser ablation method: Effect of laser wavelength. Phys Status Solidi B 252(8):1860-1867. https://doi.org/10.1002/pssb.201451614

9. Costa PM, Bourgognon M, Wang JTW, Al-Jamal KT (2016) Functionalized carbon nanotubes: From intracellular uptake and cell-related toxicity to systemic brain delivery. Journal of Controlled Release 241:200-219. https://doi.org/10.1016/j.jconrel.2016.09.033

10. Cui D, Tian F, Ozkan CS, Wang M, Gao H (2005) Effect of single wall carbon nanotubes on human HEK293 cells. Toxicology Letters 155(1):73-85. https://doi.org/10.1016/j.toxlet.2004.08.015

11. Dai CA, Hsiao CC, Weng SC, Kao AC, Liu CP, Tsai WB, Chen WS, Liu WM, Shih WP, Ma CC (2009) A membrane actuator based on an ionic polymer network and carbon nanotubes: The synergy of ionic transport and mechanical properties. Smart Mater Struct 18:8. https://doi.org/10.1088/0964$1726 / 18 / 8 / 085016$

12. Dai GP, Liu C, Liu M, Wang MZ, Cheng HM (2002) Electrochemical Hydrogen Storage Behavior of Ropes of Aligned Single-Walled Carbon Nanotubes. Nano Letters 2(5):503-506. https://doi.org/10.1021/nl020290c

13. Deshpande P, Mahendru A (2018) A review of single wall carbon nanotube: Structure and preparation. International Journal of Scientific Technology Research 7(4):132-135. https://www.ijstr.org/final-print/apr2018/A-Review-Of-Single-Wall-Carbon-Nanotube-Structure-And-Preparation.pdf

14. Ding E, Geng H, Mao L, Wang W, Wang Y, Luo Z, Wang J, Yang H (2016) Recent Research Progress of Carbon Nanotube Arrays Prepared by Plasma Enhanced Chemical Vapor Deposition Method. Materials Science Forum 852(1):308-314. https://doi.org/10.4028/www.scientific.net/MSF.852.308

Page $13 / 22$ 
15. Ebbesen TW, Ajayan PM (1992) Large-scale synthesis of carbon nanotubes. Nature 358:220-222. https://doi.org/10.1038/358220a0

16. Ema M, Hougaard KS, Kishimoto A, Honda K (2015) Reproductive and developmental toxicity of carbon-based nanomaterials: A literature review. Nanotoxicology 10(4):1-22. https://doi.org/10.3109/17435390.2015.1073811

17. Ferreira FV, Franceschi W, Menezes BRC, Biagioni AF, Coutinho AR, Cividanes LS (2019) Synthesis, Characterization, and Applications of Carbon Nanotubes. In: Yaragalla S, Mishra R, Thomas S, Kalarikkal N, Maria HJ (eds) Carbon-Based Nanofillers and Their Rubber Nanocomposites. Elsevier Inc, pp 1-451. https://doi.org/10.1016/B978-0-12-813248-7.00001-8

18. Frackowiak E, Khomenko V, Jurewicz K, Lota K, Béguin F (2006) Supercapacitors based on conducting polymers/nanotubes composites. Journal of Power Sources 153(2):413-418. https://doi.org/10.1016/j.jpowsour.2005.05.030

19. Francis AP, Devasena T (2018) Toxicity of carbon nanotubes: A review. Toxicology Industrial Health 34(3):200-210. https://doi.org/10.1177/0748233717747472

20. Gao XP, Lan Y, Pan GL, Wu F, Qu JQ, Song DY, Shen PW (2001) Electrochemical hydrogen storage by carbon nanotubes decorated with metallic nickel. Electrochem Solid-State Lett 4(10):173-175. https://doi.org/10.1149/1.1397958

21. Ghasempour R, Narei H (2018) CNT basics and characteristics. In: Rafiee R (ed) Carbon Nanotube-Reinforced Polymers: From Nanoscale to Macroscale. Elsevier Inc, pp 1-24. https://doi.org/10.1016/B978-0-323-48221-9.00001-7

22. Gopinath KP, Vo DVN, Prakash G, Adithya Joseph D, Viswanathan A, S., \& Arun J (2020) Environmental applications of carbon-based materials: a review. Environ Chem Lett. 0123456789. https://doi.org/10.1007/s10311-020-01084-9

23. Gupta N, Gupta SM, Sharma SK (2019) Carbon nanotubes: synthesis, properties and engineering applications. Carbon Letters 29(5):419-447. https://doi.org/10.1007/s42823-019-00068-2

24. Hiremath N, Mays J, Bhat G (2016) Recent Developments in Carbon Fibers and Carbon Nanotube-Based Fibers: A Review. Polymer Reviews 57(2):339368. https://doi.org/10.1080/15583724.2016.1169546

25. Hussein FH, Abdulrazzak FH (2018) Synthesis of carbon nanotubes by chemical vapor deposition. In S. Kanchi, S. Ahmed, M. I. Sabela, \& C. M. Hussain (Eds.), Nanomaterials: Biomedical, Environmental, and Engineering Applications. pp. 105-132. Scrivener Publishing LLC. https://doi.org/10.1002/9781119370383.ch4

26. Inagaki M, Kang F, Toyoda M, Konno H (2014) Carbon Nanotubes: Synthesis and Formation. In: Advanced Materials Science and Engineering of Carbon. Elsevier Inc, pp 15-40. https://doi.org/10.1016/B978-0-12-407789-8.00002-8

27. Jafar A, Alshatti Y, Ahmad A (2016) Carbon nanotube toxicity: The smallest biggest debate in medical care. Cogent Medicine 3(1):1-12. https://doi.org/10.1080/2331205x.2016.1217970

28. Jafari S (2018) Engineering applications of carbon nanotubes. In: Rafiee R (ed) Carbon Nanotube-Reinforced Polymers: From Nanoscale to Macroscale. Elsevier Inc, pp 25-40. https://doi.org/10.1016/B978-0-323-48221-9.00002-9

29. Karimi M, Solati N, Amiri M, Mirshekari H, Mohamed E, Taheri M, Hashemkhani M, Saeidi A, Estiar MA, Kiani P, Ghasemi A, Basri SMM, Aref AR, Hamblin MR (2015) Carbon nanotubes part I: Preparation of a novel and versatile drug-delivery vehicle. Expert Opinion on Drug Delivery $12(7): 1-17$. https://doi.org/10.1517/17425247.2015.1003806

30. Kaur R, Vatta P, Kaur M (2018) Carbon Nanotubes: A Review Article. International Journal for Research in Applied Science Engineering Technology 6(4):5075-5079. https://doi.org/10.22214/ijraset.2018.4827

31. Kausar A, Rafique I, Muhammad B (2016) Review of Applications of Polymer/Carbon Nanotubes and Epoxy/CNT Composites. Polymer - Plastics Technology Engineering 55,11, 1167-1191. https://doi.org/10.1080/03602559.2016.1163588

32. Kingston C, Zepp R, Andrady A, Boverhof D, Fehir R, Hawkins D, Roberts J, Sayre P, Shelton B, Sultan Y, Vejins V, Wohlleben W (2014) Release characteristics of selected carbon nanotube polymer composites. Carbon 68:33-57. https://doi.org/10.1016/j.carbon.2013.11.042

33. Kumar S, Nehra M, Kedia D, Dilbaghi N, Tankeshwar K, Kim KH (2017) Carbon nanotubes: A potential material for energy conversion and storage. Prog Energy Combust Sci 64:1-35. https://doi.org/10.1016/j.pecs.2017.10.005

34. Kurwadkar S, Hoang TV, Malwade K, Kanel SR, Harper Jr WF, Struckhoff G (2019) Application of carbon nanotubes for removal of emerging contaminants of concern in engineered water and wastewater treatment systems. Nanotechnology for Environmental Engineering 4(12):1-16. https://doi.org/10.1007/s41204-019-0059-1

35. Lamberti M, Pedata P, Sannolo N, Porto S, De Rosa A, Caraglia M (2015) Carbon nanotubes: Properties, biomedical applications, advantages and risks in patients and occupationally-exposed workers. International Journal of Immunopathology Pharmacology 28(1):4-13.

https://doi.org/10.1177/0394632015572559

36. Lanone S, Andujar P, Kermanizadeh A, Boczkowski J (2013) Determinants of carbon nanotube toxicity. Advanced Drug Delivery Reviews 65(15):1-7. https://doi.org/10.1016/j.addr.2013.07.019

37. Lin Z, Zeng Z, Gui X, Tang Z, Zou M, Cao A (2016) Carbon Nanotube Sponges, Aerogels, and Hierarchical Composites: Synthesis, Properties, and Energy Applications. Advanced Energy Materials 1600554:1-26. https://doi.org/10.1002/aenm.201600554

38. Liu X, Wang M, Zhang S, Pan B (2013) Application potential of carbon nanotubes in water treatment: A review. Journal of Environmental Sciences (China) 25(7):1263-1280. https://doi.org/10.1016/S1001-0742(12)60161-2

39. Liu Z, Tabakman S, Welsher K, Dai H (2009) Carbon nanotubes in biology and medicine: In vitro and in vivo detection, imaging and drug delivery. Nano Research 2(2):85-120. https://doi.org/10.1007/s12274-009-9009-8 
40. Loos M (2015) Production of CNTs and Risks to Health. In: Carbon Nanotube Reinforced Composites. Elsevier Inc, pp $103-123$. https://doi.org/10.1016/B978-1-4557-3195-4.00004-7

41. Ma-Hock L, Strauss V, Treumann S, Küttler K, Wohlleben W, Hofmann T, Gröters S, Wiench K, van Ravenzwaay B, Landsiedel R (2013) Comparative inhalation toxicity of multi-wall carbon nanotubes, graphene, graphite nanoplatelets and low surface carbon black. Particle Fibre Toxicology 10(23):119. https://doi.org/10.1186/1743-8977-10-23

42. Malekimoghadam R, Rafiee R (2018) Carbon Nanotubes Processing. In: Rafiee R (ed) Carbon Nanotube-Reinforced Polymers. Elsevier Inc, pp $41-59$. https://doi.org/10.1016/B978-0-323-48221-9/00003-0

43. Mamidi N (2019) Cytotoxicity Evaluation of Carbon Nanotubes for Biomedical and Tissue Engineering Applications. In H. Saleh \& S. M. M. El-Sheikh (Eds.), Perspective of Carbon Nanotubes. pp. 1-12. IntechOpen. https://doi.org/10.5772/intechopen.85899

44. Manawi YM, Ihsanullah, Samara A, Al-Ansari T, Atieh MA (2018) A review of carbon nanomaterials' synthesis via the chemical vapor deposition (CVD) method. Materials 11:5. https://doi.org/10.3390/ma11050822

45. Manke A, Luanpitpong S, Rojanasakul Y (2014) Potential Occupational Risks Associated with Pulmonary Toxicity of Carbon Nanotubes. Occupational Medicine Health Affairs 02(03):1-8. https://doi.org/10.4172/2329-6879.1000165

46. Manke A, Wang L, Rojanasakul Y (2013) Pulmonary toxicity and fibrogenic response of carbon nanotubes. Toxicol Mech Methods 23(3):196-206. https://doi.org/10.3109/15376516.2012.753967

47. Menezes BRC, De, Rodrigues KF, Fonseca BCDS, Ribas RG, Montanheiro TL D. A., \& Thim GP (2019) Recent advances in the use of carbon nanotubes as smart biomaterials. Journal of Materials Chemistry B 7(9):1343-1360. https://doi.org/10.1039/c8tb02419g

48. Mittal G, Dhand V, Rhee KY, Park SJ, Lee WR (2015) A review on carbon nanotubes and graphene as fillers in reinforced polymer nanocomposites. Journal of Industrial Engineering Chemistry 21:11-25. https://doi.org/10.1016/j.jiec.2014.03.022

49. Mohammad MI, Moosa AA, Potgieter JH, Ismael MK (2013) Carbon Nanotubes Synthesis via Arc Discharge with a Yttria Catalyst. ISRN Nanomaterials. 1-8. https://doi.org/http://dx.doi.org/10.1155/2013/785160

50. Mohanta D, Patnaik S, Sood S, Das N (2019) Carbon nanotubes: Evaluation of toxicity at biointerfaces. Journal of Pharmaceutical Analysis 9(5):293300. https://doi.org/10.1016/j.jpha.2019.04.003

51. Mubarak NM, Abdullah EC, Jayakumar NS, Sahu JN (2014) An overview on methods for the production of carbon nanotubes. Journal of Industrial Engineering Chemistry 20(4):1186-1197. https://doi.org/10.1016/j.jiec.2013.09.001

52. Narei H, Ghasempour R, Akhavan $\mathrm{O}$ (2018) Toxicity and safety issues of carbon nanotubes. In: Rafiee R (ed) Carbon Nanotube-Reinforced Polymers: From Nanoscale to Macroscale. Elsevier Inc, pp 145-171. https://doi.org/10.1016/B978-0-323-48221-9.00007-8

53. Nurazzi NM, Asyraf MRM, Khalina A, Abdullah N, Sabaruddin FA, Kamarudin SH, Ahmad S, Mahat AM, Lee CL, Aisyah HA, Norrrahim MNF, Ilyas RA, Harussani MM, Ishak MR, Sapuan SM (2021) Fabrication, functionalization, and application of carbon nanotube-reinforced polymer composite: An overview. Polymers 13(7):1-44. https://doi.org/10.3390/polym13071047

54. Nützenadel C, Züttel A, Chartouni D, Schlapbach L (1999) Electrochemical storage of hydrogen in nanotube materials. Electrochem Solid-State Lett 2(1):30-32. https://doi.org/10.1149/1.1390724

55. Pandey P, Dahiya M (2016) Carbon Nanotubes: Types, Methods of Preparation and Applications. International Journal of Pharmaceutical Science Research 1(4):15-21. https://www.researchgate.net/publication/303994564_Carbon_nanotubes_Types_methods_of_preparation_and_applications

56. Pei B, Wang W, Dunne N, Li X (2019) Applications of carbon nanotubes in bone tissue regeneration and engineering: Superiority, concerns, current advancements, and prospects. Nanomaterials 9(10):1-39. https://doi.org/10.3390/nano9101501

57. Prajapati SK, Malaiya A, Kesharwani P, Soni D, Jain A (2020) Biomedical applications and toxicities of carbon nanotubes. Drug Chem Toxicol 0(0):1-16. https://doi.org/10.1080/01480545.2019.1709492

58. Rafique MMA, Iqbal J (2011) Production of Carbon Nanotubes by Different Routes-A Review. Journal of Encapsulation Adsorption Sciences 01(02):2934. https://doi.org/10.4236/jeas.2011.12004

59. Rahman G, Najaf Z, Mehmood A, Bilal S, Shah AulHA, Mian SA, Ali G (2019) An Overview of the Recent Progress in the Synthesis and Applications of Carbon Nanotubes. C Journal of Carbon Research 5(1):1-31. https://doi.org/10.3390/c5010003

60. Rajalakshmi N, Dhathathreyan KS, Govindaraj A, Satishkumar BC (2000) Electrochemical investigation of single-walled carbon nanotubes for hydrogen storage. Electrochimica Acta 45,27:4511-4515. https://doi.org/10.1016/S0013-4686(00)00510-7

61. Rakhi RB (2019) Preparation and properties of manipulated carbon nanotube composites and applications. In: Khan A, Jawaid M, Inamuddin, \& Asiri AM (eds) Nanocarbon and its Composites: Preparation, Properties and Applications. Elsevier Ltd, pp 489-520. https://doi.org/10.1016/B978-0-08-1025093.00016-X

62. Rao R, Pint CL, Islam AE, Weatherup RS, Hofmann S, Meshot ER, Wu F, Zhou C, Dee N, Amama PB, Carpena-Nuñez J, Shi W, Plata DL, Penev ES, Yakobson BI, Balbuena PB, Bichara C, Futaba DN, Noda S, ... Hart AJ (2018) Carbon Nanotubes and Related Nanomaterials: Critical Advances and Challenges for Synthesis toward Mainstream Commercial Applications. ACS Nano 12(12):11756-11784. https://doi.org/10.1021/acsnano.8b06511

63. Raphey VR, Henna TK, Nivitha KP, Mufeedha P, Sabu C, Pramod K (2019) Advanced biomedical applications of carbon nanotube. Materials Science Engineering C 100March, 616-630. https://doi.org/10.1016/j.msec.2019.03.043

64. Raunika A, Raj SA, Jayakrishna K, Sultan MTH (2017) Carbon nanotube: A review on its mechanical properties and application in aerospace industry. IOP Conference Series: Materials Science and Engineering. 270,012027. https://doi.org/10.1088/1757-899X/270/1/012027 
65. Raval JP, Joshi P, Chejara DR (2018) Carbon nanotube for targeted drug delivery. In: Inamuddin AM, Asiri, Mohammad A (eds) Applications of Nanocomposite Materials in Drug Delivery. Elsevier Inc, pp 203-216. https://doi.org/10.1016/B978-0-12-813741-3.00009-1

66. Rege K, Raravikar NR, Kim D, Schadler LS, Ajayan PM, Dordick JS (2003) Enzyme - Polymer - Single Walled Carbon Nanotube Composites as Biocatalytic Films. Nano Letters 3(6):829-832. https://doi.org/10.1021/nl034131k

67. Saifuddin N, Raziah AZ, Junizah AR (2013) Carbon nanotubes: A review on structure and their interaction with proteins. Journal of Chemistry. 2013. https://doi.org/10.1155/2013/676815

68. Sajid MI, Jamshaid U, Jamshaid T, Zafar N, Fessi H, Elaissari A (2016) Carbon nanotubes from synthesis to in vivo biomedical applications. International Journal of Pharmaceutics 501:278-299. https://doi.org/10.1016/j.ijpharm.2016.01.064

69. Shah KA, Tali BA (2016) Synthesis of carbon nanotubes by catalytic chemical vapour deposition: A review on carbon sources, catalysts and substrates. Materials Science in Semiconductor Processing 41:67-82. https://doi.org/10.1016/j.mssp.2015.08.013

70. Shahidi S, Moazzenchi B (2018) Carbon nanotube and its applications in textile industry-A review. Journal of the Textile Institute 109(12):1653-1666. https://doi.org/10.1080/00405000.2018.1437114

71. Sharma R, Sharma AK, Sharma V (2015) Synthesis of carbon nanotubes by arc-discharge and chemical vapor deposition method with analysis of its morphology, dispersion and functionalization characteristics. Cogent Engineering 2(1094017):1-10. https://doi.org/10.1080/23311916.2015.1094017

72. Sireesha M, Babu J, Kranthi Kiran V, A. S., \& Ramakrishna S (2018) A review on carbon nanotubes in biosensor devices and their applications in medicine. Nanocomposites 4(2):36-57. https://doi.org/10.1080/20550324.2018.1478765

73. Takagi A, Hirose A, Nishimura T, Fukumori N, Ogata A, Ohashi N, Kitajima S, Kanno J (2008) Induction of mesothelioma in p53+/- mouse by intraperitoneal application of multi-wall carbon nanotube. Journal of Toxicological Sciences 33(1):105-116. https://doi.org/10.2131/jts.33.105

74. Ullah I (2018) Carbon nanotube membranes for water purification: Developments, challenges, and prospects for the future. Sep Purif Technol 209:307337. https://doi.org/10.1016/j.seppur.2018.07.043

75. Varshney K (2014) Carbon Nanotubes: A Review on Synthesis, Properties and Applications. International Journal of Engineering Research General Science 2(4):660-677. http://ijergs.org/files/documents/CARBON-81.pdf

76. Vivekanandhan S, Schreiber M, Muthuramkumar S, Misra M, Mohanty AK (2017) Carbon nanotubes from renewable feedstocks: A move toward sustainable nanofabrication. Journal of Applied Polymer Science. 44255,October 2016, 1-15. https://doi.org/10.1002/app.44255

77. Wang X, Vinodgopal K, Dai G (2019) Synthesis of Carbon Nanotubes by Catalytic Chemical Vapor Deposition. In H. E.-D. Saleh \& S. M. M. El-Sheikh (Eds.), Perspective of Carbon Nanotubes. pp. 1-19. IntechOpen. https://doi.org/0.5772/intechopen.86995

78. Yanase T, Miura T, Shiratori T, Weng M, Nagahama T, Shimada T (2019) Chemical Vapor Deposition Using Fe $1-x$ Mn x O Nanoparticles as Catalysts: How Does the Catalytic Activity of Graphitization Affect the Yields. C Journal of Carbon Research 5(46):1-9. https://doi.org/10.3390/c5030046

79. Yang L (2015) Carbon nanostructures: new materials for orthopedic applications. In: Nanotechnology-Enhanced Orthopedic Materials Fabrications, Applications and Future Trends. Elsevier Ltd, pp 97-120. https://doi.org/10.1016/B978-0-85709-844-3.00005-7

80. Zaporotskova IV, Boroznina NP, Parkhomenko YN, Kozhitov LV (2016) Carbon nanotubes: Sensor properties. A review. Modern Electronic Materials 2(4):95-105. https://doi.org/10.1016/j.moem.2017.02.002

81. Zhao J, Luo W, Xu Y, Ling J, Deng L (2020) Potential reproductive toxicity of multi-walled carbon nanotubes and their chronic exposure effects on the growth and development of Xenopus tropicalis. Science of The Total Environment 100:1-9. https://doi.org/10.1016/j.scitotenv.2020.142652

\section{Figures}

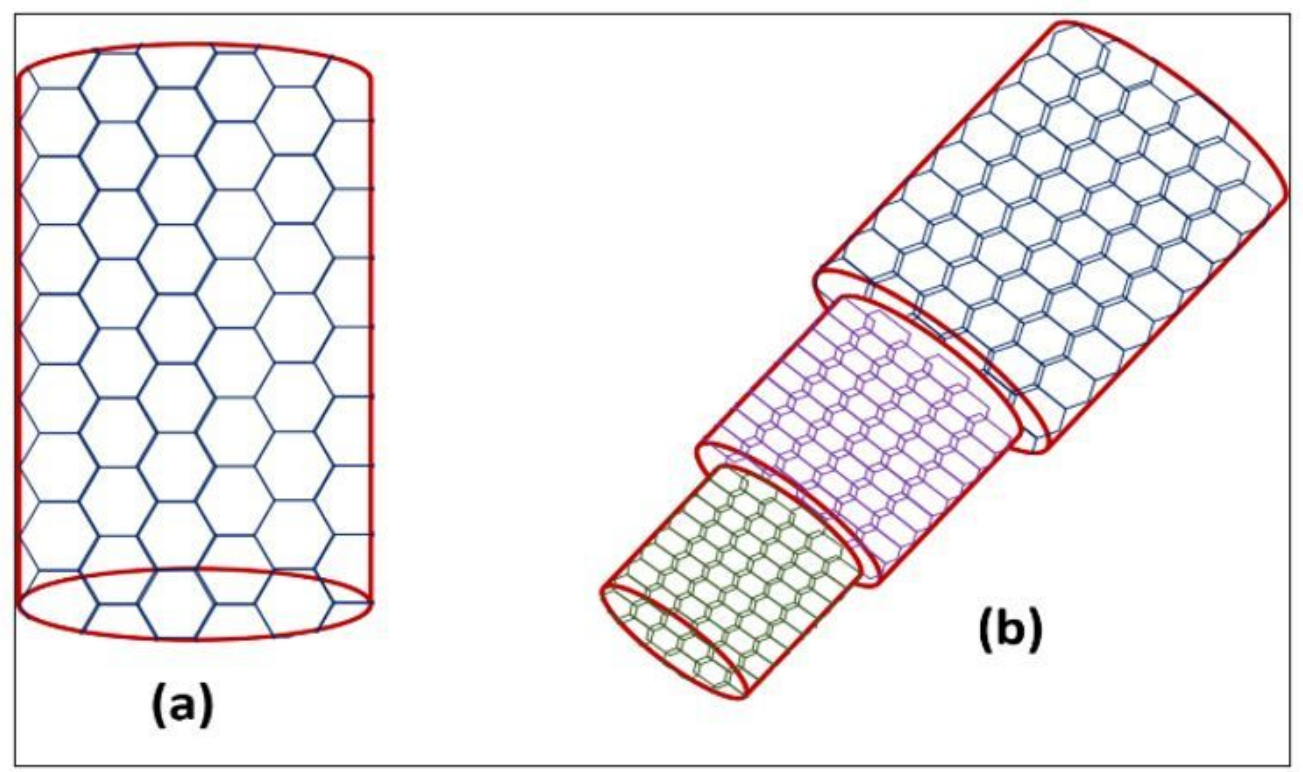

Page $16 / 22$ 
Two main types of carbon nanotubes - (a) SWCNT and (b) MWCNT (Jafar et al., 2016).

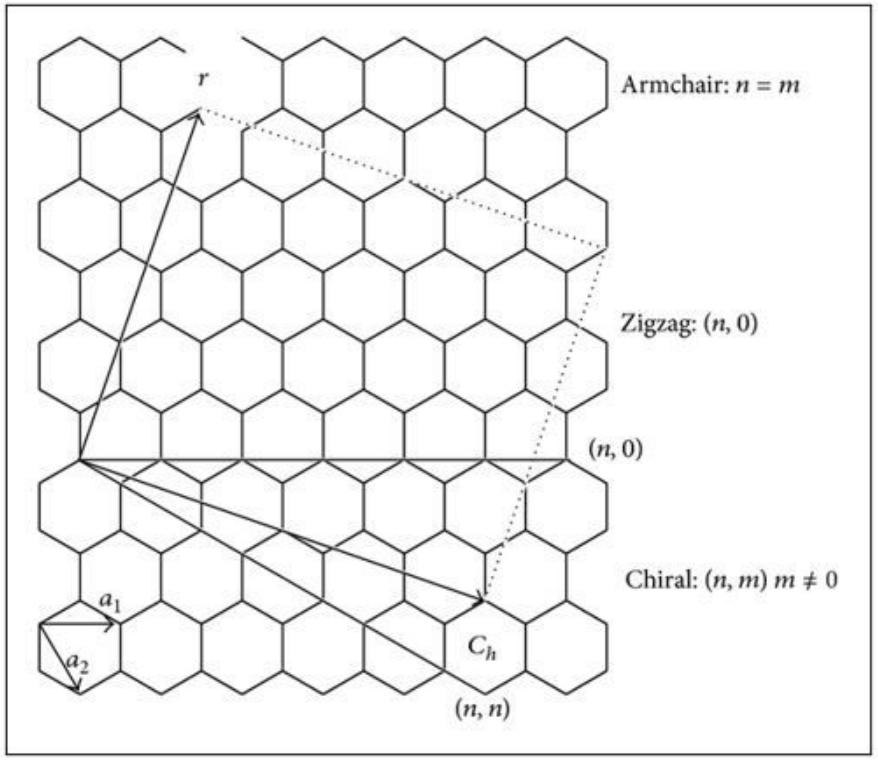

Figure 2

Schematic representation of the vector structure classification that are used to differentiate the CNT structures (Saifuddin et al., 2013).

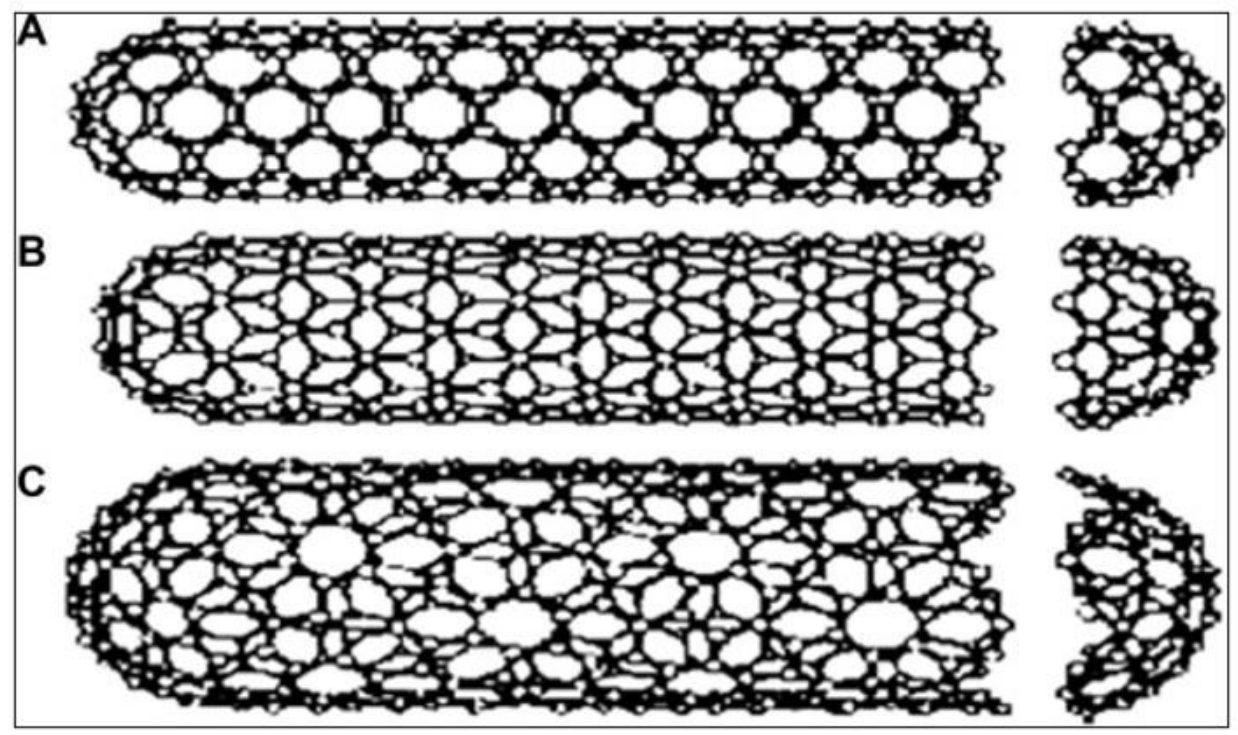

Figure 3

CNTs structure with different chirality (A: armchair; B: Zig-zag; C: Chiral) (Aqel et al., 2012). 


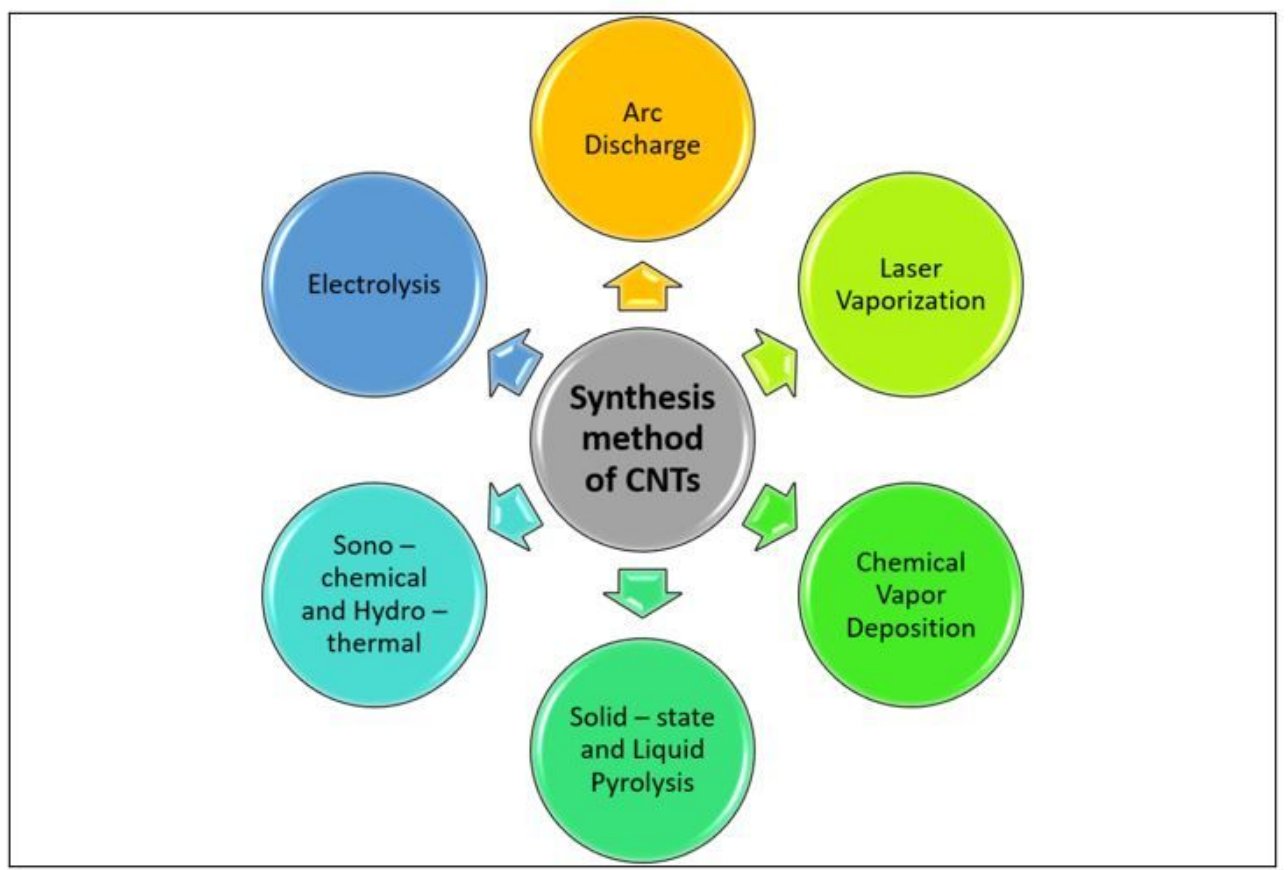

Figure 4

Various synthetic methods for CNTs (Vivekanandhan et al., 2017).

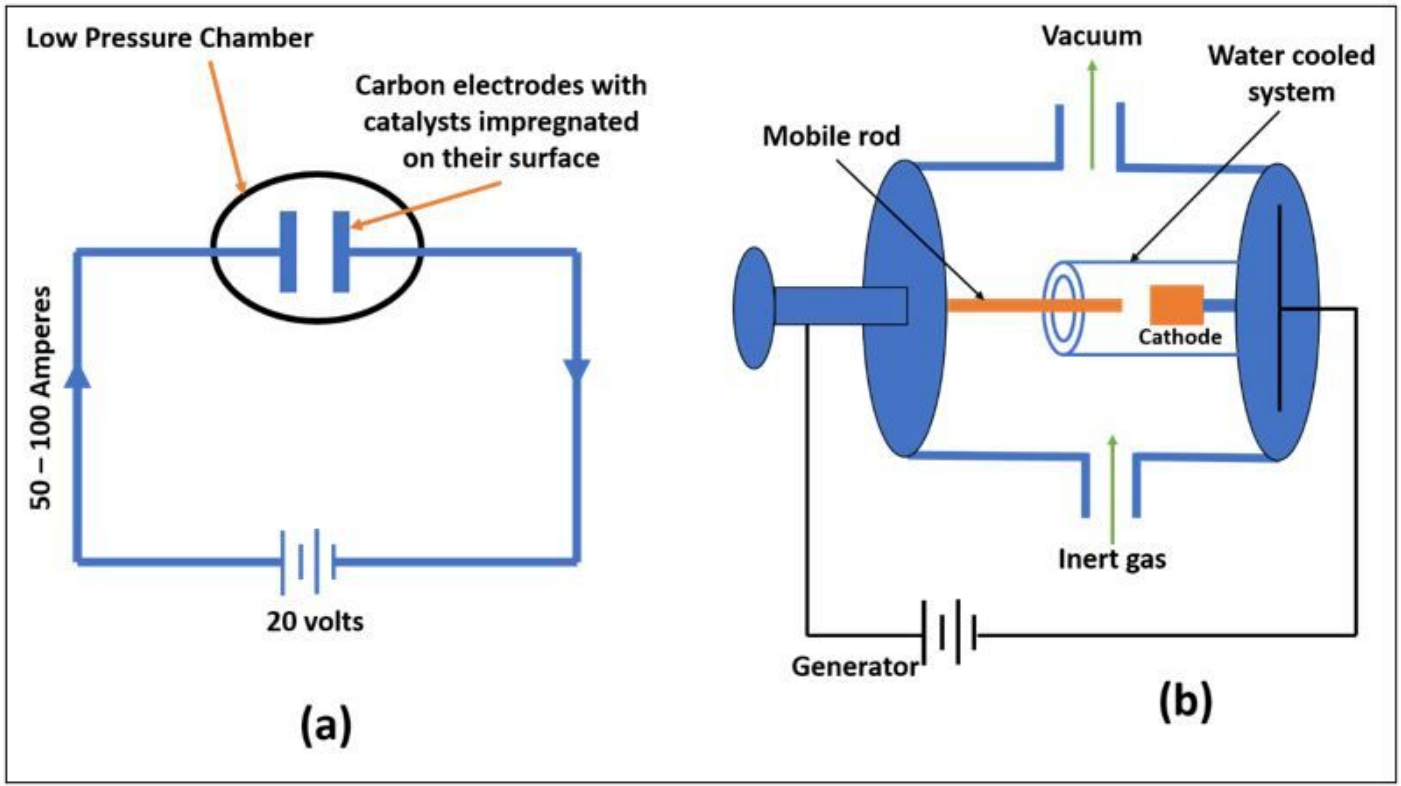

Figure 5

Schematic diagrams of arc discharge device: (a) simple schematic diagram (Sajid et al., 2016); (b) arc discharge scheme (Rakhi, 2019). 


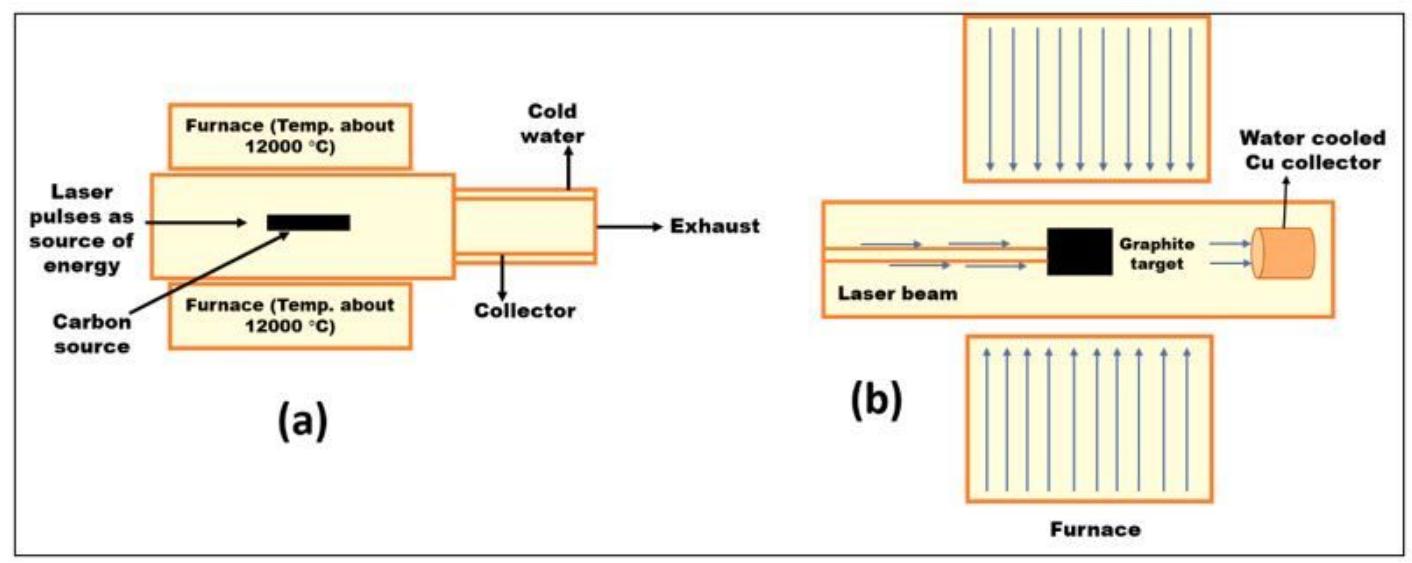

Figure 6

Schematic diagram for laser ablation technique: (a) (Sajid et al., 2016); (b)(Rakhi, 2019).

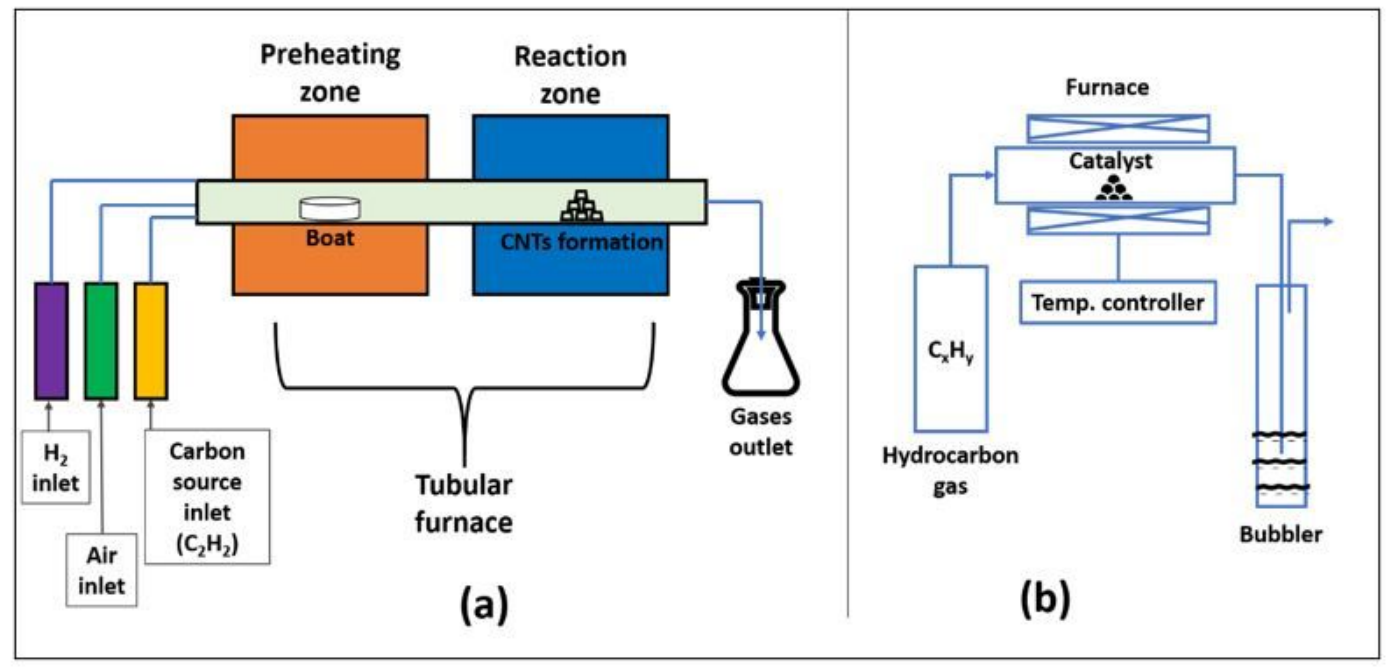

Figure 7

Schematic diagrams of CVD process: (a) (Malekimoghadam \& Rafiee, 2018); (b) (Shah \& Tali, 2016).

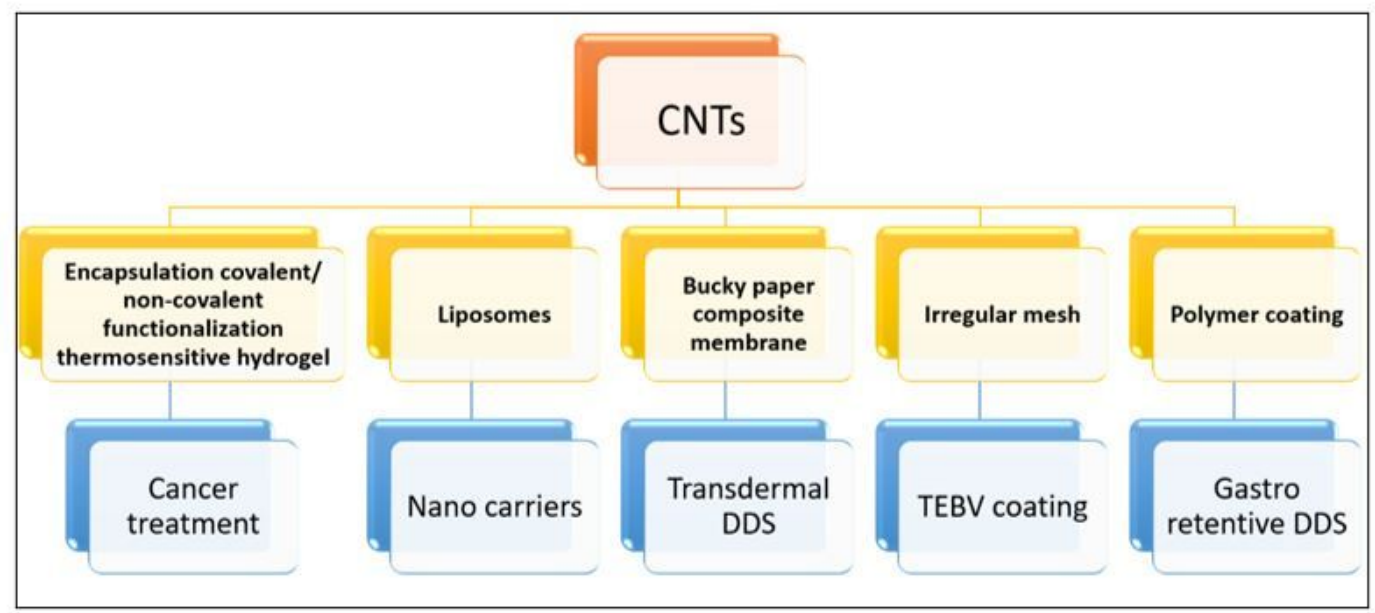

Figure 8

Current CNTs uses as drug carrier (Menezes et al., 2019). 


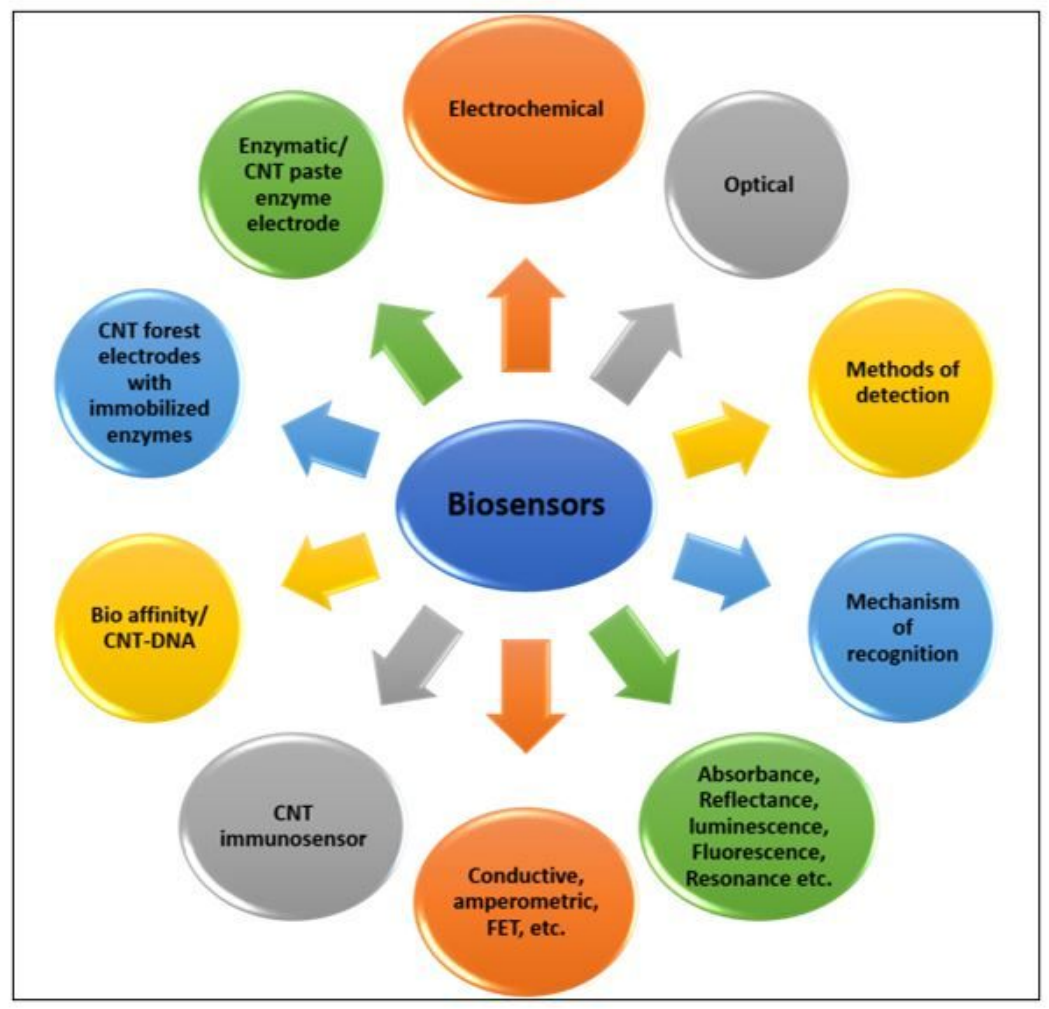

Figure 9

Various types of CNTs-based biosensors (Sireesha et al., 2018)

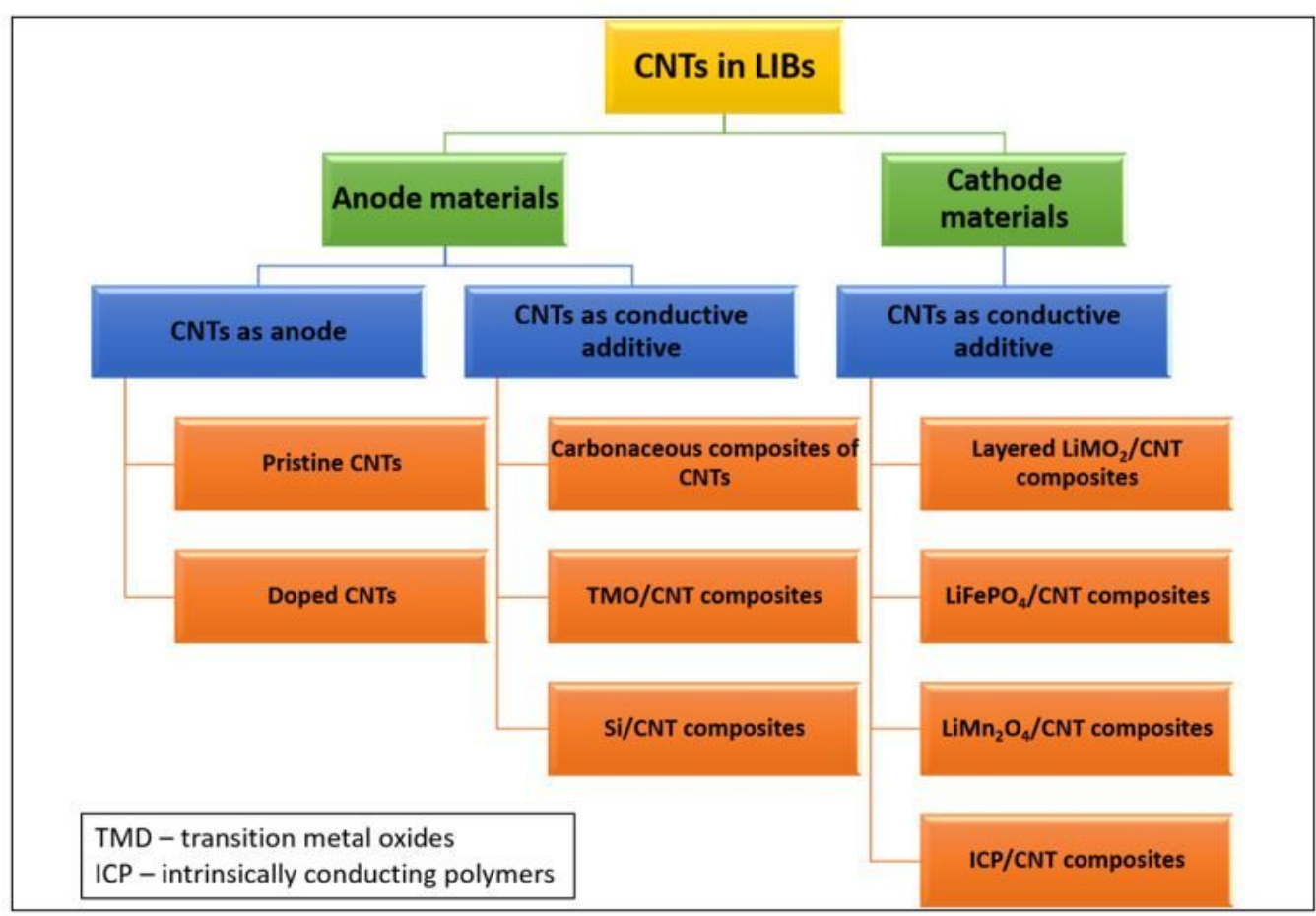

\section{Figure 10}

Various ways of LIBs incorporating CNTs (Kumar et al., 2017). 


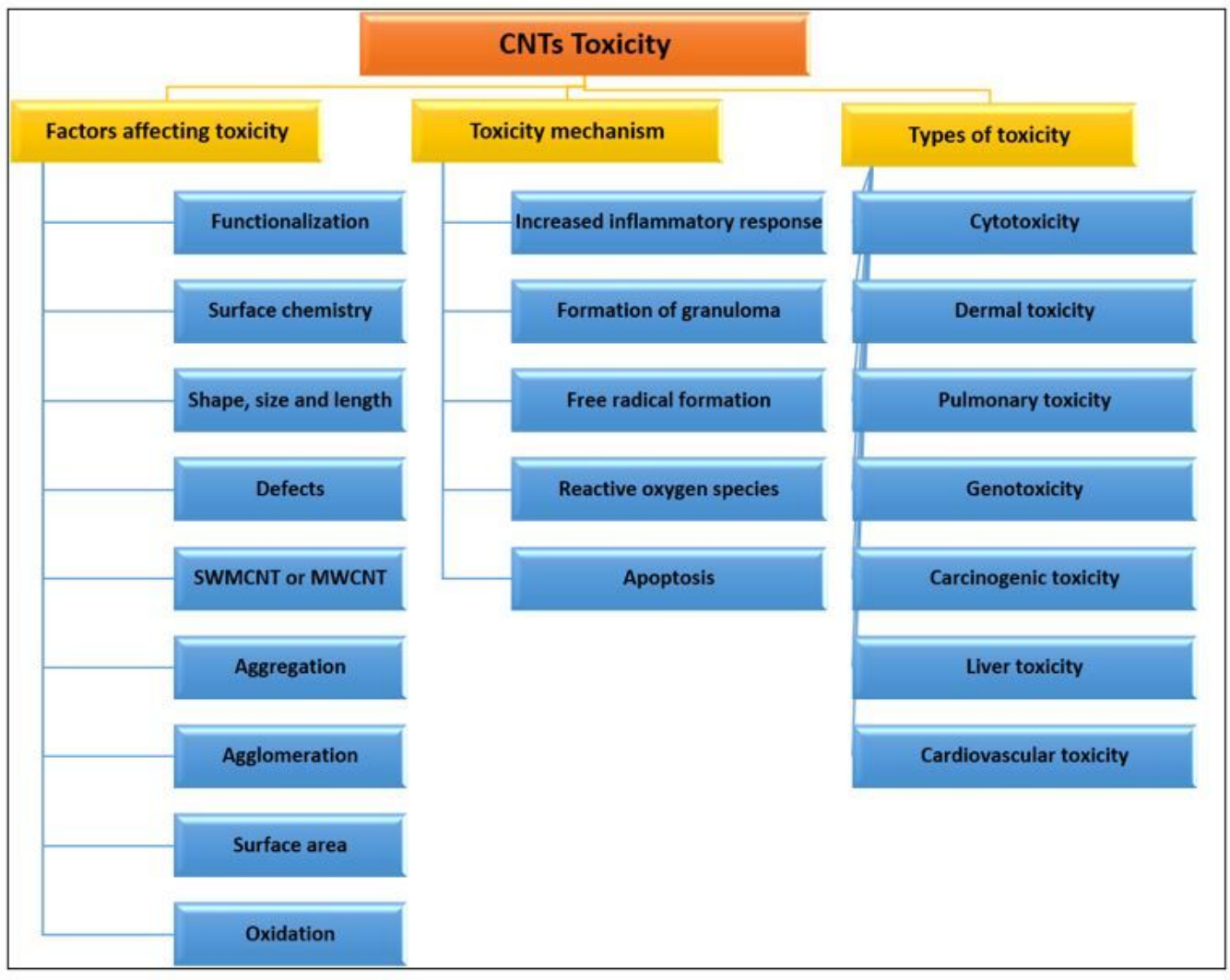

Figure 11

The outlook of CNTs' toxicity (Prajapati et al., 2020).

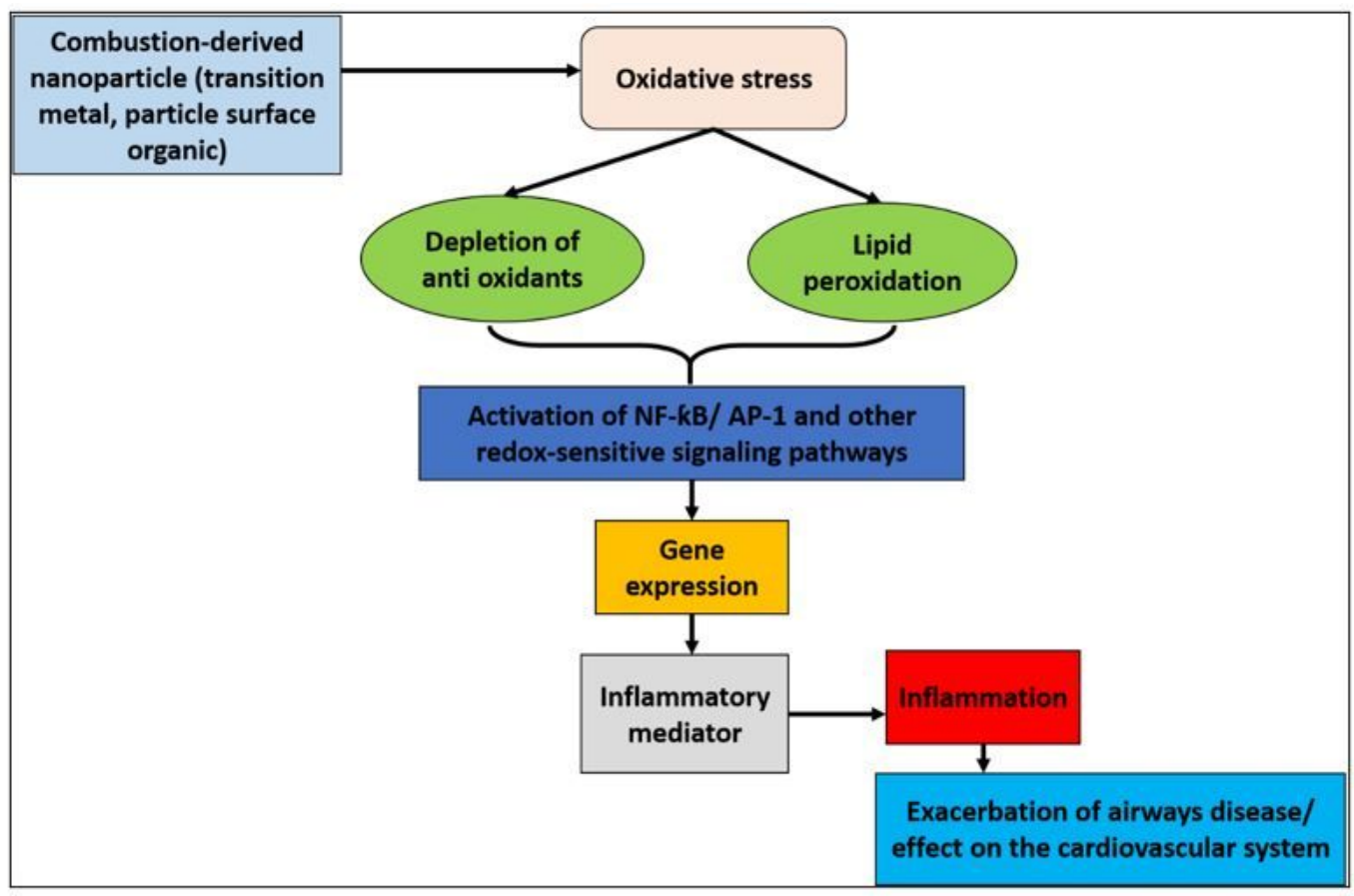

Figure 12

Sequence of events that caused inflammation (Prajapati et al., 2020). 


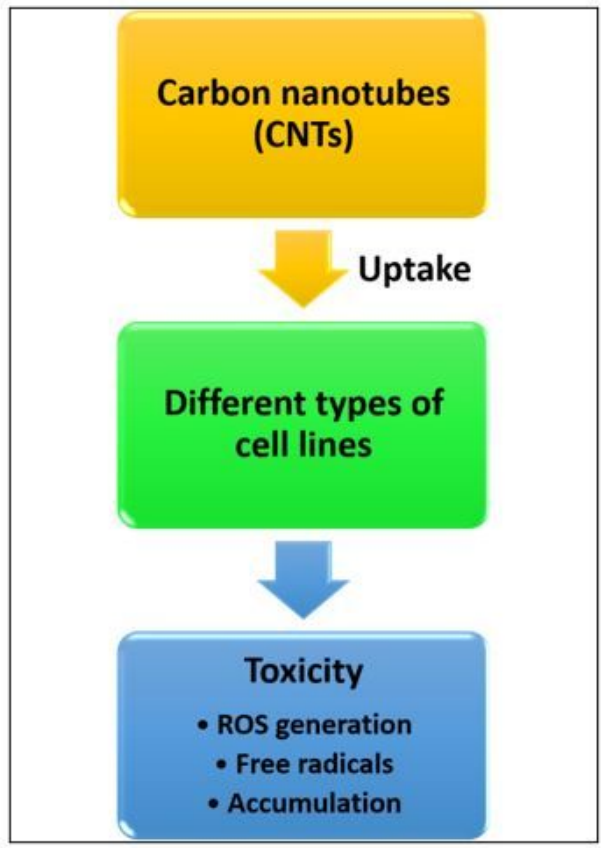

Figure 13

Modes of cytotoxicity caused by CNTs (Mohanta et al., 2019)

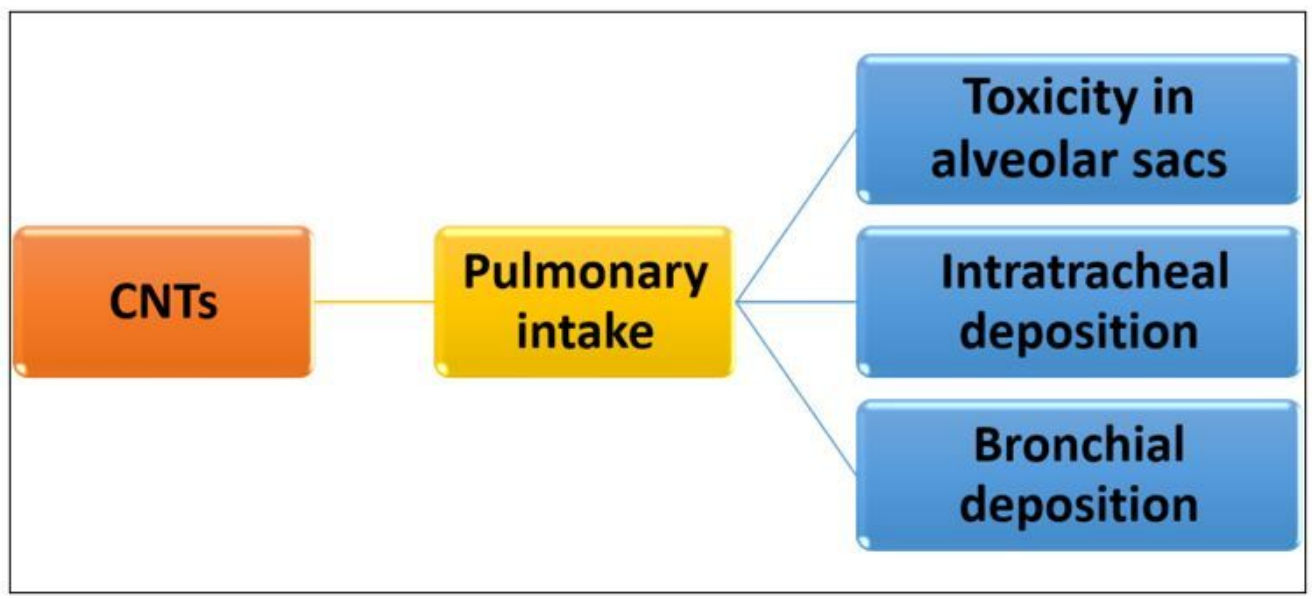

Figure 14

The pulmonary toxicity induced by CNTs (Mohanta et al., 2019). 